\title{
The diagnostic value of exercise stress testing for cardiovascular disease is more than just st segment changes: A review
}

\author{
Salaheddin Sharif ${ }^{1 *}$ and Stephen E Alway ${ }^{2}$ \\ ${ }^{1}$ Department of Physiology, Faculty of Medicine, University of Benghazi, Benghazi Libya, West Virginia University School of Medicine, Department of \\ Exercise, Libya \\ ${ }^{2}$ Physiology, Center for Cardiovascular and Respiratory Sciences Morgantown, West Virginia Clinical and Translational Science Institute, WV 26506, Libya
}

\begin{abstract}
Purpose: The objectives of this review were to: (1) identify the acute cardiovascular responses to aerobic exercise used in an exercise stress test (EST), (2) identify when and how to best conduct an EST including the stopping point, (3) identify conditions that would preclude an EST, (4) define the limiting signs and symptoms associated with an EST (5), discuss what data are needed as part of an EST and how to interpret EST data.

Methods: We identify the cardiovascular responses to an EST and when an EST should or should not be used. Finally we analyze the components of an EST and potential sensitivities, significances and predictability of the changes in the outcome data that will provide diagnosis overt cardiovascular disease, and for purposes of exercise prescription and evaluation of rehabilitation effects in cardiac patients.

Results: Although most of the focus for performing an EST traditionally has been on the diagnostic value to identify ST-segment abnormalities, an EST provides other valuable diagnostic and prognostic data including maximal oxygen consumption (predicted or measured), exercise capacity and fatigability, blood pressure and heart rate responses to exercise and recovery.

Conclusions: This review identifies the most recent standards, and guidelines of EST, which include the acute physiological response of the cardiovascular system to aerobic exercise, the use of EST in evaluation of coronary artery disease, an updated diagnostic and prognostic variables of EST, and reporting of EST.

Condensed abstract: This review identifies the most recent standards, and guidelines of the exercise stress test (EST), which include the acute physiological response of the cardiovascular system to aerobic exercise, the use of EST in evaluation of coronary artery disease, diagnostic and prognostic variables of EST, and reporting of EST.
\end{abstract}

\section{Introduction}

An exercise stress test (EST) is commonly used for the diagnosis and evaluation of cardiac disease. In addition, EST is often used to evaluate the effects of pharmacological medication on whole body function, and for exercise prescription in diseases and conditions that include but are limited to cardiac rehabilitation, obesity, diabetes and various neuropathies. EST is typically conducted using a treadmill or a cycle ergometer, while monitoring the electrocardiogram (ECG) [1], ventilatory threshold [2], blood pressure (BP) [3], heart rate (HR) [4], oxygen consumption [5], general patient self-reported effort (e.g., by a Borg Scale test) and physical appearance-including chest pain and dyspnea [6]. The American College of Cardiology (ACC), American Heart Association (AHA), American College of Sports Medicine (ACSM) and the American Society of Nuclear Cardiology all recommend an EST for diagnosing patients who are at risk for obtaining cardiovascular disease (CAD). An EST can be conducted on the majority of patients who can exercise, irrespective of age or sex [7], but some of the guidelines for athletes may need some modifications [8]. This review provides an overview of the most recent standards, and guidelines of EST, which include the acute physiological response of the cardiovascular system to aerobic exercise, the use of EST in evaluation of CAD, updated diagnostic and prognostic variables of EST, and modern reporting of EST. These guidelines are intended for healthcare professionals who currently use or are considering incorporating EST as part of health care evaluation, and rehabilitative delivery to their patients.

\section{Review of relevant literature}

Acute cardiovascular response to aerobic exercise used in an exercise stress test

EST incorporates acute aerobic exercise, which induces a requirement for increasing oxygen delivery to meet the challenges of increasing work, and to match this with sufficient perfusion of blood to the working musculature to remove the metabolic byproducts that are generated as a result of substrate utilization to generate ATP [9]. The amount of oxygen delivered to and consumed by the working skeletal muscle increases with the intensity of the exercise. Furthermore,

Correspondence to: Salaheddin Sharif MS, Department of Physiology, Faculty of Medicine, University of Benghazi, Benghazi Libya; Tel: 00218945768092 ; E-mail: salaheddin.sharif@uob.edu.ly

Received: June 20, 2016; Accepted: June 26, 2016; Published: July 31, 2016 
ventilation of expired gases increases with elevated workloads to both dispose of the greater levels of carbon dioxide, produced by increased metabolism, and to buffer lactic acid/hydrogen ions produced during the EST. Many cardiorespiratory and hemodynamic mechanisms function collectively to support increased aerobic requirement of exercise. To maximize oxygen delivery, blood flow to the working muscles increases while non-essential tissues experience a concomitant sympathetic vasoconstriction resulting in a reduction of blood flow [10]. This maximizes the distribution of cardiac output the exercising muscles [11]. The overall effect of changes include modifications of heart rate, stroke volume, cardiac output, blood flow, blood pressure and arteriovenous oxygen difference [12-14].

\section{(i) Heart rate (HR)}

Increasing workloads in an EST require an increased cardiac output (CO). Heart rate is the most important factor increasing $\mathrm{CO}$ during exercise, and it increases in linear fashion with work rate and oxygen uptake [15]. HR increases from an elevated sympathetic nervous system drive and a subsequent decrease in parasympathetic nervous system activity (i.e., decreased "vagal tone"). Furthermore, the elevated HR during exercise occurs primarily at the expense of diastolic rather than systolic blood flow 16. Although an increase in stroke volume contributes to an increase in $\mathrm{CO}$ during strenuous exercise, it is the increase in HR that is largely responsible for the CO increase [16]. In contrast to systolic blood pressure (SBP), which increases with age, maximum $\mathrm{HR}$ along with $\mathrm{HR}$ and $\mathrm{VO}(2)$ kinetics decrease with age [17]. The maximum HR is commonly used to prescribe exercise training or to predict exercise testing endpoints. The predicted maximal heart rate can be estimated from one of several available equations, some of which are derived separately for men and women. A commonly used estimation for maximal heart rate is: [maximum predicted $\mathrm{HR}=220$ age in years, +/- $12 \mathrm{bpm}$ ] [18]. Achievement of $85 \%$ of age-predicted maximal HR leads to an increase in coronary blood flow of 2-4-fold in non-stenosed coronary arteries, however, this endpoint has been challenged and as it could potentially underestimate the exercise capacity of patients [19]. Methods for an accurate evaluation of the level of effort during exercise testing is somewhat limited and, therefore should not be used as a sole criterion to determine when a test should be terminated [20]. A typical increase in HR during exercise is about $10 \mathrm{bpm}$ per metabolic equivalent (MET), where $1 \mathrm{MET}=3.5 \mathrm{ml} \mathrm{O}$ / $\mathrm{Kg} / \mathrm{Min}$ at least in persons who are not treated with beta blockers [21]. However, recent data suggests that the maximal heart rate is not a limiting factor for determining cardiovascular capacity in healthy patients [14].

\section{(ii) Stroke volume (SV)}

Stroke volume is the volume of blood ejected per heartbeat, which is equal to the difference between end-diastolic volume (EDV) and end-systolic volume (ESV) [22]. This is one of the most important components of evaluation of the efficiency of the myocardium [23], but it is difficult to measure directly without invasive approaches during a stress test or during acute exercise although indirect measures of stroke volume by electrical bioimpedance, or $\mathrm{CO}_{2}$ rebreathing, provide a reasonable estimation of the hemodynamics [23]. The increase in SV from $70-75 \mathrm{ml} /$ beat can increase to $\sim 120 \mathrm{ml} /$ beat in a healthy young adult. In general, SV is expected to increase steadily up to $50 \%$ of maximal oxygen uptake $\left(\dot{\mathrm{V} O} 2_{\max }\right)$, or aerobic capacity, and then tends to level off. The increase in SV is also dependent upon an elevation of venous return from skeletal muscles to the myocardium (Frank-starling law) and a subsequent improvement in ventricle muscle contractility as a result of heightened neurohormonal control (e.g., enhanced sympathetic activity, catecholamine hormones). Chronic exercise training may increase the left ventricular compliance and contribute to larger filling volumes leading to improved stroke volumes [24].

\section{(iii) Cardiac output (CO)}

Cardiac output provides the general description of cardiac function. It is calculated as the product of stroke volume and heart rate. In healthy adults, $\mathrm{CO}$ increases linearly with increased work rate and oxygen uptake. It can increase from basal value about $5 \mathrm{~L} / \mathrm{min}$ to a maximum of about $20-40 \mathrm{~L} / \mathrm{min}$ during strenuous exercise [25]. Maximum value of $\mathrm{CO}$ is dependent on several factors, including age, posture, level of physical conditioning, and presence of diseases. At $50 \%$ of $\dot{\mathrm{VO}} 2_{\text {max }}$ the increase in $\mathrm{CO}$ is a direct reflection on maximal SV with a lesser emphasis on maximal HR. Once $\dot{\mathrm{VO}} 2_{\text {max }}$ is beyond $50 \%$, the increase in CO due primarily to HR [26]. As a result, aged persons have a lower CO capacity, largely as a result of their lower maximal heart rate.

\section{(iv) Blood pressure (BP)}

Blood pressure is dependent on $\mathrm{CO}$ and peripheral vascular resistance, and as such, $\mathrm{BP}$ provides a noninvasive way to monitor the overall clinical "pumping" capacity of heart (20). There is linear increase in a systolic blood pressure (SBP) with increasing levels of exercise as a result of increasing CO. Normal SBP response to exercise is dependent on both sex and age. The average rise in SBP is about $8-12 \mathrm{mmHg} /$ MET and maximal values of SBP are up to $190-220 \mathrm{mmHg}$. SBP should not be allowed exceed $250 \mathrm{mmHg}[27,28]$. Diastolic blood pressure (DBP) may decrease or remain unchanged because of vasodilatation of the vascular bed and decrease of peripheral vascular resistance [29]. At the end of exercise, SBP usually decreases rapidly, largely from the decrease in $\mathrm{CO}$ that matches the reduction of the exercise load at the conclusion of the EST. Typically, systolic BP will return to basal levels and may drop below pre-exercise levels for several hours [30]. On the other hand, syncope which can occur suddenly during recovery from a maximal exercise stress test or even acute exercise, (i.e., postexercise syncope), represents a failure to maintain or regulate blood pressure appropriately, and may arise from reduced muscle pump augmentation of blood return to the right side of the heart along with vasodilation [31]. Manual assessment of both diastolic (DBP) and systolic blood pressure (SBP) during an EST requires a skilled evaluator because it is difficult to accurately identify the Kortotkoff sounds as a result of the noise of the treadmill etc. Even measuring resting DBP, can be challenging due to auditory problems, the ability to recognize the fifth Korotkoff sound, or an auscultatory gap. The measurement of BP through automatic equipment, with the right technique, offers many advantages over the manual technique, having verified its utility and clinical validity [16].

\section{(v) Blood flow (BF) response}

At rest, $15-20 \%$ of $\mathrm{CO}$ is distributed to skeletal muscles; the remainder goes to the brain, heart, and visceral organs. With exercise, $\mathrm{CO}$ and BF increase 4-5 times. BF is directed to active skeletal muscles and respiratory muscles, blood supply to the brain is maintained at resting level, and $85-90 \%$ of $\mathrm{CO}$ is directed to exercising muscles and to skin in order to help dissipate heat production caused by the increase in metabolism, and it is directed away from the viscera. Increases in coronary blood flow with intensity during exercise $(260 \mathrm{ml} / \mathrm{min}$ to $900 \mathrm{ml} / \mathrm{min}$ at $\max$ ) is experienced. The redistribution of $\mathrm{BF}$ during 
exercise is due to sympathetic and hormonal effect on smooth muscles of blood vessels [16,32].

\section{(vi) Oxygen difference response}

Normally oxygen content in arterial blood is approximately 20 $\mathrm{ml} / \mathrm{dl}$ and oxygen content in venous blood is about $15 \mathrm{ml} / \mathrm{dl}[33$. Arteriovenous oxygen difference is about $5 \mathrm{ml} / \mathrm{dl}$ at rest, which is a coefficient of $25 \%$. During acute exercise, oxygen extraction increases so that the arteriovenous oxygen difference is $\sim 15 \mathrm{ml} / \mathrm{dl}$ with a coefficient of $75 \%$ [33,34]. However, while long-term training is associated with an increase in cardiac output, there is a modest or no increase in arteriovenous oxygen difference [33].

\section{(vii) Oxygen uptake (Maximal oxygen consumption $\dot{\mathrm{V}} \mathrm{O} 2_{\text {max }}$ )}

Maximal oxygen consumption is the maximal amount of oxygen that can be consumed in one minute and is reported in absolute terms as liters per minute or in relative terms as milliliters per kilogram of body weight per minute [35]. $\dot{\mathrm{VO}} 2_{\text {max }}$ is equal to the product of maximum $\mathrm{CO}$ and maximum arteriovenous oxygen difference and it is influenced by age, sex, exercise habits, heredity, obesity levels and cardiovascular clinical status $[22,36] . \dot{\mathrm{VO}} 2_{\text {max }}$ increases linearly with work intensity up to a point beyond which, an increase in work intensity will not elicit an increase in oxygen uptake. It is good indicator for cardiorespiratory fitness and it is the best single predictor of the amount of aerobic work one can perform. Typical oxygen uptake for a young male at rest is 250 $\mathrm{ml} / \mathrm{min}$ and under maximal conditions and this can be increased to $3600 \mathrm{ml} / \mathrm{min}$. $\dot{\mathrm{VO}} 2_{\text {max }}$ can be estimated from the peak work intensity achieved during an EST [29].

\section{(viii) Myocardial oxygen consumption}

Primary factors that determine myocardial oxygen consumption include HR, myocardial contractility, and ventricular wall stress (i.e., the product of SBP and ventricular volume). Myocardial oxygen consumption is inversely related to myocardial wall thickness. It can be measured during an EST by the double product rate (also known as rate-pressure product), which is the product of HR and SBP [37]. Myocardial oxygen consumption is directly proportional to coronary artery blood flow. During exercise, coronary blood flow increases as much as 5 -fold above the resting value. It should be noted that a patient with CAD will not have insufficient coronary blood flow to the affected myocardial tissue that is required to meet the metabolic demands of the cardiac muscle during exercise. Consequently, exercise induced angina, ST-segment depression and myocardial ischemia occur at the same rate-pressure product rather than at the same external workload in patients with coronary artery diseases (CAD) [37]. This suggests the existence of an ischemic threshold at which myocardial oxygen consumption exceeds myocardial oxygen supply. The rate pressure product can estimate the maximal workload that can be performed by the left ventricle.

\section{Approach for conducting an exercise stress test}

Although a variety of personnel including physicians, exercise physiologists, nurses and rehabilitative technicians can conduct the EST. The American College of Physicians (ACP), American College of Cardiology (ACC), and American Heart Association (AHA) task force statement on clinical competence in EST, recommend that graded EST should be performed only by well-trained qualified professional with an adequate knowledge of exercise physiology and preferably certification (e.g., Registered Clinical Exercise Physiologist) [38]. In addition, they should have suitable life-saving skills including certification in advanced cardiopulmonary resuscitation, emergency medication, and a defibrillator should be immediately available at the exercise laboratory in the event of an emergency. Even though EST is considered a safe test, there are always risks associated with such evaluations. For example, there are reports of cardiac events and sudden death during an EST [39]. Surveys have shown that 0-6 deaths or cardiac arrests occur per 10,000 tests and 2-10 myocardial infractions per 10,000 tests might be expected, but these estimates will vary markedly with the prevalence and severity of underlying heart disease in the tested population $[40,41]$. The evaluator should also be aware of other rare complications that could occur during an EST including arrhythmias, acute coronary syndromes, heart failure, hypotension, syncope, shock and death [29].

\section{Indication of exercise stress test for diagnosis or prognosis}

EST may be used for diagnostic, prognostic, therapeutic, and functional applications especially in regards to exercise prescription [42]. The most common use of EST is the diagnosis and evaluation of suspected CAD. Understanding the purpose of the individual exercise test allows the test supervisor to determine appropriate methodology and to select test end points that maximize test safety and obtain the needed diagnostic and prognostic information. Cardiovascular risk assessment has great importance for exercise prescription with the goal of improving clinical outcomes [43]. Table 1 outlines the primary indications for considering EST as an evaluative tool $[43,44]$.

\section{Contraindications to exercise stress test}

As with any test there are risks and therefore it is no surprise that there are both absolute and relative contraindications to EST. The potential benefits of test results clearly need to be weighted against any potential negative outcomes for the patient with the idea that the EST is to "do no harm" to the patient. Pre-exercise test evaluation and taking medical history help identify potential contraindications and increase the safety of EST. Generally patients with absolute contraindications should not perform the EST until such conditions are stabilized. Patients with relative contraindications may be tested after evaluation of the risk/benefit ratio and it can be superseded if benefits outweigh risk of exercise, but they should be closely supervised and monitored throughout the test procedures. In addition, patients with relative contraindications to EST can be tested using low level end points. Table 2 outlines both absolute and relative contraindications to EST that cover most patients $[43,45]$.

\section{Obtaining an adequate workload}

To provide an accurate assessment of cardiovascular function, the EST should be conducted using parameters that include: $85 \%$ of age-predicted maximal HR 46, a pressure-rate product $>20,000$, where coronary artery blood flow increases up to 2-3 fold in non-stenosed coronary arteries [47], and am ischemia which includes angina and STsegment changes 48 . If a patient cannot achieve an adequate workload

Table 1. Primary indicators for ordering an exercise stress test.

\begin{tabular}{|l|l|l|}
\hline Diagnostic & Therapeutic & Evaluation \& Function Capacity \\
\hline Evaluation of suspected CAD & Antianginal therapy & After myocardial infarction \\
\hline Evaluation of high risk patients & Antiarrhythmic therapy & After coronary bypass \\
\hline After myocardial infraction & Antihypertensive therapy & After cardiac surgery \\
\hline After angioplasty & Bronchodilators agents & Exercise prescription \\
\hline Arrhythmia provocation & Vasodilators agents & Cardiopulmonary \\
\hline Peripheral vascular disease & & Rehabilitation \\
\hline
\end{tabular}


Table 2. Contraindications to exercise stress test.

\begin{tabular}{|l|l|}
\hline Absolute Contraindications & Relative Contraindications \\
\hline Acute myocardial infarction (MI), within 2 days or other acute cardiac event & Known of left main coronary artery stenosis \\
\hline A recent significant change in the resting ECG suggesting ischemia & Moderate aortic stenosis \\
\hline Unstable angina & Resting hypertension with systolic or diastolic blood pressures $>200 / 110$ mm Hg \\
\hline Uncontrolled cardiac arrhythmia causing hemodynamic compromise & Tachyarrhythmias or bradydysrhthmis \\
\hline Acute myocarditis ,acute pericarditis and active endocarditis & Ventricular aneurysm \\
\hline Symptomatic severe aortic stenosis & Complete heart block \\
\hline Decompensated heart failure & Hypertrophic obstructive cardiomyopathy with severe resting gradient \\
\hline Acute pulmonary embolism, pulmonary infarction, or deep vein thrombosis & Recent stroke or transient ischemic attack \\
\hline Acute aortic dissection & Neuromuscular or rheumatoid diseases that are exacerbated by exercise \\
\hline Acute systemic infection & Uncorrected medical disease (anemia, diabetes, and hyperthyroidism) \\
\hline Physical disability & Chronic infectious disease (AIDS, hepatitis) \\
\hline & Mental and physical impairment with limited ability to cooperate \\
\hline
\end{tabular}

Table 3. Determining the point for terminating the exercise stress test.

\begin{tabular}{|c|c|}
\hline Absolute Indications & Relative Indications \\
\hline $\begin{array}{l}\text { ST-segment elevation }(>1.0 \mathrm{~mm} \text { ) in leads without preexisting } \mathrm{Q} \text { waves because of } \\
\text { prior MI (other than aVR, aVL, and V1) }\end{array}$ & $\begin{array}{l}\text { ST depression ( }>2 \mathrm{~mm} \text { horizontal or downsloping ST-segment depression), in a patient with } \\
\text { suspected ischemia }\end{array}$ \\
\hline $\begin{array}{l}\text { Drop in SBP of }>10 \mathrm{~mm} \mathrm{Hg} \text {, despite an increase in workload when accompanied by } \\
\text { any other evidence of ischemia }\end{array}$ & $\begin{array}{l}\text { Drop in SBP of }>10 \mathrm{~mm} \mathrm{Hg} \text { from baseline despite an increase in workload, in the absence of other } \\
\text { evidence of ischemia }\end{array}$ \\
\hline Moderately severe angina (defined as 3 on standard angina scale) & Increasing chest pain \\
\hline Increasing nervous system symptoms (e.g., ataxia, dizziness, near syncope) & Fatigue, shortness of breath, wheezing, leg cramps, or claudication \\
\hline Signs of poor perfusion (cyanosis or pallor) & $\begin{array}{l}\text { Arrhythmias other than sustained VT, including multifocal ectopy, ventricular triplets, } \\
\text { supraventricular tachycardia, heart block and bradyarrhythmias }\end{array}$ \\
\hline $\begin{array}{l}\text { Sustained ventricular tachycardia (VT) or other arrhythmia, including second- or } \\
\text { third-degree atrioventricular (AV) block, that interferes with normal maintenance of } \\
\text { cardiac output during exercise }\end{array}$ & Hypertensive response $(\mathrm{SBP}>250 \mathrm{~mm} \mathrm{Hg}$ and/or $\mathrm{DBP}>115 \mathrm{mmHg}$ ) \\
\hline Technical difficulties in monitoring the ECG or SBP & $\begin{array}{l}\text { Development of bundle-branch block or intraventricular conduction delay that cannot immediately } \\
\text { be distinguished from VT }\end{array}$ \\
\hline The patient's request to stop & \\
\hline
\end{tabular}

and cardiovascular stress stimulus for any reason, the results of the EST are of limited utility [49].

\section{Termination of exercise stress test}

The supervisor of the EST has an important role in determining when to stop the test and this is generally based upon the purpose of EST in patient. Symptom-limited testing is appropriate for general evaluation, but it can be modified in several situations. Absolute indications are clear, where relative indications may be superseded by the supervisor of EST. Table 3 outlines the indications of terminating EST $[44,50]$.

\section{Interpretation of exercise stress test (EST) data}

It is very important to collect and evaluate an accurate patient medical history because this may influence both the test results and the information collected in EST [51]. There are several medical conditions that can have an impact on EST interpretation including orthopedic diseases, lung diseases, neurologic diseases, and deconditioning or prolonged bedrest. Other things to consider include drug history, abnormal resting ECG, left ventricular hypertrophy [44,51]. Interpretation of EST data should include ECG, functional capacity, and the hemodynamic response to the graded exercise. A thorough understanding of the best interpretation of the EST will provide optimal diagnostic, prognostic and therapeutic evaluation and prescription of rehabilitative programs for the patient.

\section{The diagnostic variables of exercise stress test}

1. The ECG changes during exercise stress test
The normal ECG findings and response to exercise include the following [29,44]:

- $\quad$ P wave increases in height and change in morphology

- $\mathrm{R}$ wave decreases in height

- J point becomes depressed

- $\quad$ ST segment becomes sharply upward sloping

- QT interval shortens

- $\mathrm{T}$ wave decreases in height in early exercise but increase in higher exercise

- High-frequency content of the QRS power spectrum increases with exercise and shortening of QRS duration.

Some changes of ECG wave morphology may be indicative of an underlying pathology. For example, although it is normal for the QRS duration to decrease with exercise, the QRS duration may increase in patients with angina and left ventricular dysfunction. Exercise induced $\mathrm{P}$-wave changes are rarely seen and are questionable significance. Although $\mathrm{R}$ wave in aVL lead ( $\mathrm{RaVL}$ ) is strongly correlated with left ventricular mass index (LVMI) assessed by transthoracic echocardiography [52]. Many factors affect R-wave amplitude; consequently, such changes during exercise have no independent predictive power $[53,54]$.

Abnormal ST-segment changes have been the standard criteria for diagnosis of CAD for more than half a century. The ST level is measured relative to the end of the $\mathrm{PR}$ segment (the $\mathrm{P}-\mathrm{Q}$ junction) because the $\mathrm{T}(\mathrm{U})-\mathrm{P}$ segment during exercise is difficult or impossible to measure 
when HR are fast. Three or more consecutive beats in the same lead with a stable baseline, and the average magnitude and tangent direction of displacement at 60-80 ms after the J-point determined should be identified, either manually or by use of computer-averaged complexes [55,56]. The $\mathrm{R}$ wave in aVL lead (RaVL) is strongly correlated with left ventricular mass index (LVMI) assessed by transthoracic echocardiography [52,57].

ECG from an EST is not always straightforward to interpret. For example, ST-Segment changes may be affected by abnormal resting ECG (bundle branch block, left ventricular hypertrophy, digitalis drug) so resting ECG responses should be examined carefully. Healthy subjects may have J-point depression and an enhanced T-wave at high intensities exercise and also recovery. Depression of J-point that leads to marked ST-Segment upsloping may be caused by competition between normal repolarization and delayed terminal depolarization forces rather than by ischemia [58-60].

\section{ST-Segment depression}

ST-segment depression is a lowered J-point and a slope that occurs 60-80 ms after the J-point. This is the most common indicator of CAD. The standard criterion for a positive test is more than $1 \mathrm{~mm}$ horizontal or downsloping ST-segment depression with the PR segment as the isoelectric baseline of the ECG [61-65]. It must be present in at least 3 consecutive beats in 2 or more contiguous ECG leads. ST-segment depression does not identify the ischemic region nor the coronary arteries involved, however, if it occurs during recovery after EST, this is predicative of cardiac death [66-70]. Having moreleads with ST-segment depression indicates a greater severity of the disease. Downsloping STsegment depression is a stronger predictor of CAD than horizontal depression and both are more predictive than upsloping depression. Upsloping ST-segment depression is not strongly predictive of existing $\mathrm{CAD}$ in general populations, although and it might be associated with increased risk of future coronary events, especially in higher-risk men [71-73]. Upsloping ST-segment depression is generally defined as an "equivocal" test response, which is a major reason for the reduced sensitivity of EST (more false positive results) [59,74]. In presence of abnormal resting ECG, ST-segment depression during EST is less specific for CAD. In patients with left bundle branch block, ST-segment changes during exercise are not diagnostic with respect to evidence of ischemia. In right branch bundle block, exercise induced ST-segment depression in leads $\mathrm{V}_{1}, \mathrm{~V}_{2}$ and $\mathrm{V}_{3}$ are not diagnostic; on other hand, ST-segment changes in leads $\mathrm{V}_{4}, \mathrm{~V}_{5}, \mathrm{~V}_{6}$ (lateral leads) or leads II,III,aVF (inferior leads) may be indicative of CAD [75-78].

\section{ST-Segment elevation}

The standard criterion for positivity is more than $1 \mathrm{~mm}$ horizontal or upsloping ST-segment elevation, measured $80 \mathrm{~ms}$ after the J-point, and seen in 3 or more consecutive beats [44,79-82]. ST-segment elevation in leads with $\mathrm{Q}$ wave consistent with a prior myocardial infraction may be indicative of wall motion abnormalities from an aneurysm, and is associated with akinesis of the left ventricular wall, and residual viability within an infarcted area [83-85]. Exercise induced ST-segment elevation in $\mathrm{V}_{1}$ and $\mathrm{V}_{2}$ leads, but not the aVR lead, is significant for diagnosis of CAD $[1,79,86,87]$. ST-segment elevation signifies severe transmural ischemia caused by multi-vessel CAD, or coronary artery spasm (Prinzmetal's angina) [29,88-90]. In contrast to ST-segment depression, ST-segment elevation does identify the ischemic region; further, the territory of ischemia is greater in patients with exerciseinduced ST-segment elevation than with ST-segment depression

\section{Limiting signs and symptoms}

Perceived symptoms are one of the most an important component of EST which includes angina, dyspnea, and perceived exertion [29,9497]. Angina without ECG changes is predictive of CAD and is even more predictive with associated ST-segment depression $[94,98,99]$. About $30 \%$ of patients who have ST-segment changes develop chest pain [100-102]. Angina during EST correlates with the severity of CAD, with the exception of diabetic patients [103-107]. Dyspnea which limits the test is indicative of a poor prognosis as compared to angina or leg fatigue $[108,109]$. It is important to obtain a careful description of all perceived symptoms during EST from the patient, and to document what the patient considers to be the primary limiting factor and patient's general appearance should be carefully observed during EST. Signs of poor perfusion, such as cyanosis, pallor, and nervous system symptoms, such as ataxia, dizziness, and vertigo, serve as absolute test termination criteria [110]. Even though the diagnostic value has not been confirmed, cardiac auscultation during the recovery stage of EST, could be indicative of altered cardiac function. For example, "Gallop" sounds, a palpable precordial bulge, or the development of a mitral regurgitant murmur after exercise, could suggest left ventricular dysfunction [111-113].

\section{Diagnostic value of exercise stress test}

The diagnostic value of an EST to detect CAD is influenced by the principle of conditional probability [114]. The probability of a patient having CAD is not estimated correctly from EST result alone [115]. It also depends on the likelihood of having disease before the test. Bayes' theorem states that the posttest probability of having CAD is determined by CAD probability before EST and the probability the test will provide a true result [29]. The probability of a patient having CAD before EST is related to the medical history (age, sex, risk factor of cardiovascular disease) and symptoms (chest pain). Diagnostic EST is most valuable in patients with an intermediate pretest probability group, because the test result has the largest potential effect on diagnostic outcome. Therefore, an EST cannot be used to rule in or rule out CAD unless the probability of CAD is taken into account [44]. Generally EST is not considered for asymptomatic patients but may be useful when multiple risk factors are present.

In low risk patients (as men aged $\leq 30 \&$ women aged $\leq 40$ ) a positive test result is more likely to be a false positive, and negative results add little new information. In a high risk population, such as those aged over 50 with typical angina symptoms, a negative result cannot rule out $\mathrm{CAD}$, although the results may be of some prognostic value [44]. The factors that determine the predicative outcome of EST are the sensitivity and specificity of the test procedure and the prevalence of CAD in patients. Sensitivity and specificity determine how effective an EST is in making correct diagnoses, and separates patients with disease from healthy subjects without disease, respectively. From a meta-analysis of multiple studies, $1 \mathrm{~mm}$ of horizontal or downsloping ST-segment depression has been selected as the discriminating point and has a sensitivity of $68 \%$ and specificity of $77 \% 116$. Disease prevalence is an important determinant of the predicative value of EST. Moreover, non ECG variables (functional capacity, MET, hemodynamic, symptoms of angina and dyspnea) should be considered in the overall interpretation of EST results.

\section{Sensitivity}

Sensitivity of EST represents the percentage of patients with CAD who have abnormal test results (significant ST-segment positive 
changes). EST sensitivity for diagnosis of CAD regularly is based on consequent cardiac catheterization determined coronary artery stenosis of $70-75 \%$ at least one vessel [44]. A true positive test reveals $1.0 \mathrm{~mm}$ or more horizontal or downsloping ST-segment depression. False-negative test results show no any diagnostic ECG changes and fail to identify patients with CAD. EST sensitivity is decreased by inadequate myocardial stress, drugs that reduce myocardial ischemia ( $\beta$-blockers, nitrates, calcium channel blockers) and insufficient ECG leads monitoring. EST is most accurate for diagnostic CAD by applying validated multivariate scores which include pretest risk markers, STsegment changes and other EST responses [117-121]. However, preexisting ECG change (left ventricular hypertrophy, left bundle branch block, Wolff-Parkinson-White syndrome) limit the ability to interpret EST results. Generally, an EST has a higher sensitivity in

patients with triple-vessel disease than in those with double-vessel disease, which in turn is higher than those with single-vessel disease $[122,123]$. Therefore, EST sensitivity will vary with the extent of disease, even though all patients will have a diagnosis of CAD.

\section{Specificity}

Specificity of EST is indicative of the percentage of patients without CAD who have normal EST results (non-significant ST-segment negative changes) [44]. Specificity may be affected by drugs such as digoxin, by baseline ECG patterns, and by left ventricular hypertrophy. A true-negative test correctly identifies a patient without CAD. Specificity is higher than sensitivity when workup bias is removed and EST can have a lower specificity if it is used in patients who are more likely to have false-positive results $[8,124,125]$.

Sensitivity and specificity are inversely correlated. All tests have a range of inversely related sensitivities and specificities that can be selected by specifying a discriminant or a diagnostic cutoff point [126]. The sensitivity and specificity of EST are limited by the general use of angiographic CAD as the diagnostic "gold standard," and hence most data are derived from studies in which patients underwent both EST and cardiac catheterization. Because patients selected for coronary arteriography are more likely to have obstructive CAD, these data are subject to an experimental bias that inflates the estimated sensitivity and deflates the specificity. The diagnostic accuracy of a test will also be influenced by criteria that are used to determine whether an adequate level of stress has been achieved. This often is defined as having attained $85 \%$ of maximal age-predicted heart rate. There are shortcomings to using this calculation for diagnostic purposes, and it should not be used as a sole reason to terminate the test $[20,127,128]$.

\section{Predictive values}

The predictive value of an EST is a measurement of how accurately a test result (positive or negative) correctly identifies whether or not the patient has $\mathrm{CAD}$, and it also helps define the diagnostic value of the test itself. The predictive value of a positive test is the percentage of those patients with an abnormal test who have CAD. EST should never be classified as negative unless the patient has attained as adequate level of myocardial stress.

The predictive value cannot be estimated directly from sensitivity or specificity, because it depends on the prevalence of CAD in patients who have been tested [44]. EST has a higher positive predictive value and lower negative predictive value when used in high-prevalence patients. For example, an EST that shows ST-segment depression in an older patient with angina will most likely have a true positive result, whereas a false-positive result is more likely to be found in a young asymptomatic subject that does not have cardiac risk factors.

Examination of interactions among sensitivity, specificity, and predictive values are necessary to improve the use of diagnostic EST. Clinical factors that affect the likelihood of CAD prior to the patient undergoing EST include age, sex, symptoms, and traditional risk factors - hyperlipidemia, diabetes mellitus and hypertension. Based on the patient's likelihood of disease and the performance characteristics of the outcome on EST, the posttest likelihood of obstructive CAD can be estimated for a given patient [29]. Table 4 outlines the equation of sensitivity, specificity, predictive value of EST.

\section{Causes of a false positive exercise stress test}

A false positive EST indicates an exercise-induced ST-segment depression in the absence of significant obstructive CAD. It is associated with pathophysiology such as increased left ventricular mass, pressure overload, or higher oxygen consumption, and decrease blood flow to the subendocardium [129]. In addition, sympathetic nerve stimulation, drugs, electrolyte abnormalities may affect the ST-segment at high HR resulting in false positive results [130-135].

\section{Causes of a false negative exercise stress test}

A false negative EST is associated with males, single vessel disease, failure to achieve adequate workload, drugs like $\beta$-blockers agents which decrease HR, and contractility of ventricles and increase coronary blood flow with exercise, and high probability of CAD [136]. To obtain accurate EST results, it is necessary for drugs that decrease HR or BP, such as $\beta$-blockers, be discontinued days before the test. This requires the consultation and supervision of the patient's cardiologist. Table 5 outlines the causes of false positive and false negative of EST.

\section{Discussion}

\section{The prognostic variables of exercise stress test}

EST has a very important role in prognosis of cardiovascular diseases, prediction of future cardiac events and mortality. Even as alternative diagnostic strategies such as imaging modalities and serologic markers become more common, the use of EST continues to increase and can give a complimentary perspective [29,137-142]. There are several prognostic variables that can be derived from EST which include HR adjustment of ST-segment depression, functional capacity, exercise duration, BP Abnormalities, chronotropic incompetence, HR recovery, and ventricular dysrhythmias.

\section{HR adjustment of ST-Segment depression}

Exercise induced ST-segment depression occurs during high workloads when there is coronary artery obstruction and an increased oxygen demand. This is physiological principal of imbalance between oxygen supply and oxygen demand. HR changes are related to changes

Table 4. Defining: Sensitivity, Specificity, Predictive value of exercise stress test.

Sensitivity $=\mathrm{TP} /(\mathrm{TP}+\mathrm{FN})=\%$ of patients with $\mathrm{CAD}$ who have a positive test Specificity $=\mathrm{TN} /(\mathrm{TN}+\mathrm{FP})=\%$ of patients without $\mathrm{CAD}$ who have a negative test Positive predictive test $=$ $\mathrm{TP} /(\mathrm{TP}+\mathrm{FP})=\%$ of patients with a positive test who have CAD

Negative predictive test $=\mathrm{TN} /(\mathrm{TN}+\mathrm{FN})=\%$ of patients with a negative test who do not have CAD

Abbreviations: TP, true positive; FP, false positive; TN, true negative; FN false negative 
Table 5. Causes of false positive and false negative exercise stress test.

\begin{tabular}{|l|l|}
\hline $\begin{array}{l}\text { Aortic valve diseases } \\
\text { Athletics }\end{array}$ & $\begin{array}{l}\text { Inadequate workload or failure to reach an } \\
\text { ischemic threshold }\end{array}$ \\
\hline $\begin{array}{l}\text { Digoxin agents } \\
\text { Estrogen agent } \\
\text { Female sex }\end{array}$ & $\begin{array}{l}\text { B-Blocker agents } \\
\text { Calcium-Blocker agents }\end{array}$ \\
\hline $\begin{array}{l}\text { Left bundle branch block } \\
\text { Left ventricular hypertrophy Heart failure }\end{array}$ & $\begin{array}{l}\text { Single vessel CAD } \\
\text { Male gender }\end{array}$ \\
\hline $\begin{array}{l}\text { Hypertrophic cardiomyopathy } \\
\text { Sever Hypertension }\end{array}$ & $\begin{array}{l}\text { Left bundle branch block } \\
\text { Nitrates }\end{array}$ \\
\hline $\begin{array}{l}\text { Mitral valve diseases } \\
\text { Hyperventilation }\end{array}$ & Right bundle branch block \\
\hline $\begin{array}{l}\text { Intraventricular conduction defects } \\
\text { Coronary spasm (Microvascular disease) }\end{array}$ & High exercise DBP \\
\hline $\begin{array}{l}\text { Right bundle branch block } \\
\text { Supraventricular tachycardia }\end{array}$ & Technical or observer error \\
\hline
\end{tabular}

in myocardial oxygen demand, resulting from low coronary blood flow, and ST-segment depression changes that occur during graded EST as a result of coronary artery obstruction $[143,144]$. Therefore, it is physiologically important to adjust observed ST-segment depression for the change in $\mathrm{HR}$ associated with its production to derive indices of obstructive CAD [122,123,145]. Two methods of heart rate adjustment of ST-segment depression during EST have been proposed. The first is the ST/HR index is the ratio of maximum ST-segment change (measured in $\mathrm{mV}$ ) to the maximal change in HR from rest to peak exercise (measured in beats.min-1) and it is considered to be abnormal if ST/HR exceeds $1.6 \mu \mathrm{V} / \mathrm{bpm}[29,137-142]$. The ST/HR index $=($ Peak exercise - upright control ST)/(Peak exercise - upright control HR). The ST/HR index increases the sensitivity for diagnosis of CAD and predicts mortality and cardiovascular events [29,146-149]. Data from Kingfield's group $[137,142,150]$ suggest that the ST/HR index should be used in routine EST evaluation.

The second approach is to use the ST/HR slope, which is measured by linear regression analysis of the ST-segment depression in individual leads, to the HR at the end of each stage of exercise. An ST/ HR slope more than $2.4 \mu \mathrm{V} / \mathrm{bpm}$ is considered abnormal, and values more than $6 \mu \mathrm{V} / \mathrm{bpm}$ is suggestive of anatomically extensive disease, including three vessels or left main CAD [151,152]. The slope is used with gradual increments exercise protocol in HR, such as the Cornell protocol, because large increments in rate between stages of the Bruce protocol limit the ability to calculate statistically valid ST/HR slopes by regression [153-156]. ST/HR slope increases sensitivity for diagnosis of CAD and for identification of anatomically and functionally severe CAD when markedly abnormal.

\section{Functional capacity}

Functional capacity is a key predictor and prognostic marker of risk for adverse events in apparently healthy individuals, those at increased risk for cardiovascular disease, and all patient populations [3,157-160]. Functional capacity is an estimate of the maximal oxygen consumption for any given workload and is measured in units of metabolic equivalents (MET). Functional capacity is a valuable predictor of CAD in both men and women. It has been determined that higher functional capacity can indicate a lower prevalence of CAD [101,161-165]. Bourque et al. found that patients who achieved more than 10 METs had a very low prevalence of CAD compared with those who achieved less than 7 METs [71,166]. It has been shown that functional capacity in METs is a very strong independent predictor of all-cause and cardiovascular mortality [167-169]. Each 1-MET increase in functional capacity leads to $13-15 \%$ decrease in rates of all-cause death and cardiovascular events [170,171]. However, the use of functional capacity in routine clinical care is problematic because of a lack of standardization. Functional capacity is strongly related to age and gender. Thus, an estimated functional capacity of 7 METs in a 40-year-old man would be prognostically more concerning than the same value in a 60 -year-old woman $[136,157,158,172-174]$. Functional capacity is higher in men than women, and decreases with age for both genders [175-177]. Some investigators have characterized functional capacity as abnormal if it is less than 5 METs in women or less than 7 METs in men [136,157,158,172-174]. Regardless of angiographic findings, patients with CAD who achieve more than 10 METs have an excellent prognosis [178-182]. Poor functional capacity ( $<5$ METs) in patients with known CAD or prior $\mathrm{MI}$ is associated with an increased risk of cardiac events [178-183]. Further evaluation is required when there is a sudden reduction in patient's functional capacity.

\section{Exercise duration}

In an EST, healthy well-trained subjects can complete the Bruce protocol, in a maximum of 27 minutes whereas, the average middleaged adult takes 8-10 minutes to complete this test [184,185]. Exercise duration is a good measure of functional capacity and it is considered an independent and strong predictor for mortality and cardiac events on a standard protocol in patients with known or suspected cardiovascular diseases [184,185]. Functional capacity, which is normally lower in women than men, decreases with age, however, exercise duration keeps its prognostic value after adjusting for both age and sex. In subsets of patients with $\mathrm{CAD}$, exercise duration has been shown to provide risk stratification. More than three decades ago, the Coronary Artery Surgery Study (CASS) first showed that survival at 4 years was $100 \%$ in patients with CAD and preserved left ventricular function who achieved stage 5 of EST and walk more than 12 minutes [186-191].

\section{Blood pressure (BP) abnormalities}

In response to exercise, there is both diagnostic and prognostic value in evaluating BP abnormalities. Hypotensive and hypertensive BP to exercise have been defined in various ways $[184,185]$. Exercise induced hypotension occurs when there is a decrease in SBP below the resting value or an initial increase in SBP during early exercise followed by a decrease of more than $10 \mathrm{mmHg}$ [192-195]. It is a potential indication to terminate exercise, especially in the presence of evidence for ischemia or other known heart disease 29. The pathophysiology of exercise-induced hypotension is a failure of cardiac output to increase during exercise and is associated with severe CAD and left ventricular systolic dysfunction [196,197]. Exercise induced hypotension has been shown to be associated with a threefold higher risk of cardiac events over two years and it is a marker of increased risk of adverse events [198-200].

Exercise induced hypertension is defined as an increase in SBP $>210 \mathrm{mmHg}$ for men and $>190 \mathrm{mmHg}$ for women [192-195,201-205]. An increase of DBP more than $10 \mathrm{mmHg}$ above the resting value or an absolute value of $90 \mathrm{mmHg}$ also is considered abnormal and could predict increased likelihood of CAD. EST termination should be made when SBP is more than $250 \mathrm{mmHg}$ and DBP more than $115 \mathrm{mmHg}$, respectively [202,206-208]. A resting SBP $>200 \mathrm{mmHg}$ and DBP $>110$ $\mathrm{mmHg}$ are considered relative contraindications to EST. Exercise induced hypertension may indicate an increased risk for future hypertension, left ventricular hypertrophy, and cardiovascular events [192-195,201-205,209]. In the Coronary Risk Development in Young Adults cohort, participants with exercise-induced hypertension were 1.7 times more likely to have developed hypertension at 5-year follow- 
up than those with a normal response. Patients with an increase in SBP $>20 \mathrm{mmHg} / \mathrm{min}$ during aerobic exercise or whose SBP did not decrease two minutes after exercise have a 5-fold increased risk of stroke $[210,211]$. Abnormally delayed decreasing of SBP during the recovery stage of EST is predictive of severe CAD [212]. An increase of SBP $>10$ $\mathrm{mmHg} / \mathrm{min}$ for 2 minutes in recovery stage of EST was associated with risk of future myocardial infraction [40,213-215]. Exercise induced hypertension may cause ECG changes and ST-segment depression in the absence obstruction of the coronary artery [216,217].

\section{Chronotropic incompetence}

Chronotropic incompetence occurs when the HR fails to increase with an increase in workload. It also occurs when a minimum of $85 \%$ of age-predicted maximum HR cannot be reached for patients who are not talking $\beta$-blocker agents [218-220]. However, 65-70\% chronotropic incompetence cutoff points have been shown to stratify to heart failure patients with the works prognosis [221]. It is associated with cardiac disease, sick sinus syndrome, congestive heart failure, medications, and advanced age [29,137-142,222]. Regardless of whether or not a patient is taking $\beta$-blocker agents or calcium-channel blocker agentschronotropic incompetence independently predicts cardiac event and all-cause mortality [223-226]. There are different measures for defining chronotropic incompetence were used in different studies, based on resting HR, exercise protocol, age, and drugs ( $\beta$-blocker agents). Chronotropic response or index is calculated as: Chronotropic index $=$ $\left(\mathrm{HR}_{\text {peak }}-\mathrm{HR}_{\text {rest }}\right) /\left(220-\mathrm{HR}_{\text {rest }}\right) \%[29,49,137-142]$. The difference between peak HR and resting HR is the HR reserve. It is abnormal if it is less than $80 \%$ and less than $62 \%$ for patients on $\beta$-blocker agents. There are challenges to the use of chronotropic response include calcium channel blockers, pacemakers, and atrial fibrillation.

\section{Heart rate recovery (HRR)}

HR normally slows during the recovery stage of EST, as it is closely related to autonomic function and parasympathetic nervous system reactivation. Abnormal heart rate recovery $\mathrm{HRR}$ is failure of $\mathrm{HR}$ to decrease 12 beats or more during the first minute at recovery stage of EST while patients are standing [157,158,201,227-229]. An abnormal $\mathrm{HRR}$ is associated decreased parasympathetic reactivation (vagal tone), increased sympathetic activity and autonomic imbalance [198,230,231]. Excessive sympathetic activity, increases HR, BP, cardiac workload, hemodynamic stress, endothelial dysfunction, coronary artery spasm, left ventricular hypertrophy, serious arrhythmias, stroke, and cardiac mortality. In contrast, increased parasympathetic activity decreases $\mathrm{HR}$, BP and myocardial oxygen consumption, so it is protective against ischemia related dysrhythmias [232-236]. Abnormal HHR is independently a predictor of all-cause mortality and cardiovascular events [101,157,158,201,227-229,237,238].

Difficulties in characterizing HRR represent a challenge for its use in routine EST. Several factors have influence on HRR-the type of recovery protocol of EST (complete cessation of exercise or cool-down) and body position (supine, sitting, standing). Suggested thresholds for abnormal responses include [29,137-142]:

- Standing position HR should slow down by at least 12 beats/ minute at 1 minute

- Sitting position at least 22 beats/minute at 2 minutes

- Supine position at least 18 beats/minute at 1 minute

Both chronotropic incompetence and abnormal HRR can predict risk of death. HRR appears to be modifiable, as improvements in HRR have been reported following exercise training of cardiac patients $[11,165,239-241]$

\section{Ventricular ectopy}

Ventricular ectopy is the most common cardiac arrhythmia during exercise. In general, ventricular ectopy includes paired premature ventricular contractions (PVC), multiform PVC, and a run of ventricular tachycardia. It is of concern in patients with a family history of sudden death or medical history of cardiomyopathy, valvular heart disease, or CAD. Isolated PVCs occur during EST in $30-40 \%$ of healthy people and in $50-60 \%$ of patients with cardiovascular disease 44. Although, the diagnostic and prognostic values of ventricular ectopy during exercise and recovery are still controversial 29, Frolkis et al. showed that frequent ventricular ectopy during recovery stage of EST is better a predictor of 5-year mortality than ventricular ectopy during exercise dose 242. In addition, other studies have shown that ventricular ectopy during exercise and the recovery stage of EST was associated with an increased death rate. In addition, it was found to be an independent predictor of increased morbidity and mortality [243-246]. The exact relationship between exercise induced ventricular ectopy, ischemia, and left ventricular function are currently unclear.

\section{Application to practice}

\section{Integrated exercise stress test scores}

Patient management decisions are based on risk and prognostic evaluation. The data obtained from an EST is most useful when used along with other clinical information, such as ECG data and other clinical hemodynamic variables [247-250]. There are several multivariate prognostic scores that can be measured based on traditional ECG data, functional and hemodynamic variables of EST, including the Duke Treadmill Score (DTS), the VA/ Froelicher score, and the Veteran Score 44. The Duke Treadmill Score is the most common risk score used in labs and it has been developed from more than 2000 patients (30\% women) with CAD who completed an EST using the Bruce protocol and this was followed by diagnostic cardiac catheterization $[175,228,246]$. The Duke Treadmill Score includes exercise duration, ST-segment depression, and the presence and nature of angina. The Duke Treadmill Score is calculated as follows:

- DTS=exercise time - (5 X ST-segment deviation $)$ - $(4 \mathrm{X}$ angina score index)

- Exercise time is measured in minutes when using the Bruce protocol.

- ST deviation is the net ST-segment deviation in any lead other than aVR, and angina score is given a value of (no angina $=0$, nonlimiting angina $=1$, and test-limiting angina $=2$ ).

The Duke Treadmill Score is classified into risk as follows: Low-risk $(\geq 5)$, Moderate risk $(-10$ to +4$)$, and High-risk $(\leq-11)$. This score is applicable in providing valuable diagnostic and prognostic information in both men and women. It predicts cardiovascular mortality and allcause mortality in symptomatic and asymptomatic men and women [175]. Alternatively, a score by Lauer et al. has been proposed that has integrated more clinical risk factors (age, sex, lipid level, and smoking history) with EST variables. For predicting all-cause mortality it may be superior to the Duke Treadmill Score [246].

\section{Data to include in a current exercise stress report}

Current standards for an EST report include diagnostic, prognostic 
Table 6. Data that is needed in an EST report.

\begin{tabular}{|l|l|l|}
\hline Variable & Response and result & Comment \\
\hline ST-segment & Negative, positive, equivocal & Normal or abnormal \\
\hline ST/HR index & $\leq 1.6 \mathrm{~V} / \mathrm{bpm}$ & *Consistent with absence of CAD \\
\hline & $>1.6 \mathrm{~V} / \mathrm{bpm}$ & *Consistent with presence of CAD \& $\uparrow$ \\
\hline & & cardiovascular risk \\
\hline Functional capacity & $\mathrm{Xx} \mathrm{MET}$ & high/low risk of all-cause mortality \\
\hline Blood pressure & Normal, high, low & No $\uparrow \uparrow$ risk of developing HTN \\
\hline chronotropic index & $0 . \mathrm{xx} \mathrm{if} \leq 0.8$ or & $\uparrow / \downarrow$ risk of death compared with DTS. \\
\hline Heart rate recovery & $\leq 0.62$ on $\beta$-blockers & $\uparrow / \downarrow$ risk of death \\
\hline PVCs during recovery stage & $\mathrm{xx}$ bpm & $\uparrow / \downarrow$ risk of death \\
\hline DTS & Presence or absence & $*$ Low, moderate, high risk \\
\hline & $\mathrm{xx}$ & *Predicts a cardiac mortality of X $\% /$ \\
\hline & & year over the next 5 years. \\
\hline
\end{tabular}

Abbreviation: CAD, coronary artery disease; HTN, hypertension; DTS, Duke Treadmill Score, $\uparrow$ increased; $\downarrow$, Decreased.

variables data and the reason for stopping the test. Also, if there is a presence of chest pain at peak exercise it is necessary to note that in the report. An EST has moved beyond solely evaluating the ST segment and thus, cardiac laboratories and clinicians should revise the former standard report (positive, negative and equivocal) to the new comprehensive report which includes all variables data of the test to evaluate patients with CAD. In Table 6 we list the minimal data that should be included in an EST report [29,137-142,175].

\section{Summary}

Exercise stress testing for evaluation of cardiovascular dysfunction or disease has traditionally relied on ST-segment abnormalities to identify or predict cardiovascular disease. However, an exercise stress test provides the opportunity to obtain additional objective diagnostic and prognostic data and use these data to more completely evaluate the extent of cardiovascular disease. This includes obtaining maximal oxygen consumption (predicted or measured), exercise capacity and fatigability, as well as blood pressure and heart rate responses as well as a comprehensive analysis of ECG abnormalities. We have reviewed standards, and guidelines for exercise stress testing, that have included the acute physiological responses of the cardiovascular system to aerobic exercise. The use of exercise stress test can be used to evaluate the presence and extent of coronary artery disease and the data can be used to prescribe an appropriate exercise rehabilitative program by which to reduce the effects of the disease process. Finally, the exercise stress test can be used to evaluate the effectiveness of pharmacological or exercise interventions to improve the effects of cardiovascular disease. Thus, a comprehensive exercise stress test and not just a pharmacological stress test 96 should be used unless otherwise contraindicated, to provide a full cardiovascular assessment of a patient's cardiovascular function (Table 6).

\section{Acknowledgements}

Submission statement: All authors have read and approved the manuscript. This manuscript has not been published previously, nor is it under consideration for publication elsewhere.

\section{References}

1. Amit G, Granot Y, Abboud S (2014) Quantifying QRS changes during myocardial ischemia: Insights from high frequency electrocardiography. J Electrocardiol 47: 505511. [Crossref]

2. Bosch PR, Holzapfel S, Traustadottir T (2015) Feasibility of Measuring Ventilatory Threshold in Adults With Stroke-Induced Hemiparesis: Implications for Exercise Prescription. Arch Phys Med Rehabil 96: 1779-1784. [Crossref]
3. O'Neal WT, Qureshi WT, Blaha MJ, Keteyian SJ, Brawner CA, et al. (2015) Systolic Blood Pressure Response During Exercise Stress Testing: The Henry Ford ExercIse Testing (FIT) Project. J Am Heart Assoc 4. [Crossref]

4. Lipinski MJ, Vetrovec GW, Gorelik D, Froelicher VF (2005) The importance of heart rate recovery in patients with heart failure or left ventricular systolic dysfunction. $J$ Card Fail 11: 624-630. [Crossref]

5. Lim HS, Theodosiou M (2014) Exercise ventilatory parameters for the diagnosis of reactive pulmonary hypertension in patients with heart failure. J Card Fail 20: 650657. [Crossref]

6. Matsuki R, Kisaka T, Ozono R, Kinoshita H, Sada Y, et al. (2013) Characteristics of patients with severe heart failure exhibiting exercise oscillatory ventilation. Clin Exp Hypertens 35: 267-272. [Crossref]

7. Goff DC Jr, Lloyd-Jones DM, Bennett G, et al. (2013) ACC/AHA guideline on the assessment of cardiovascular risk: a report of the American College of Cardiology/ American Heart Association Task Force on Practice Guidelines. J Am Coll Cardiol 63: 2935-2959.

8. Dunn TP, Pickham D, Aggarwal S, Saini D, Kumar N, et al. (2015) Limitations of Current AHA Guidelines and Proposal of New Guidelines for the Preparticipation Examination of Athletes. Clin J Sport Med 25: 472-477. [Crossref]

9. Opitz D, Lenzen E, Opiolka A, et al. (2013) Endurance training alters basal erythrocyte MCT-1 contents and affects the lactate distribution between plasma and red blood cells in T2DM men following maximal exercise. Can J Physiol Pharmacol 2015: 1-7.

10. Nielsen MS (2015) Sympathetic vasoconstriction takes an unexpected pannexin detour. Sci Signal 8: fs4. [Crossref]

11. Andersen MJ, Olson TP, Melenovsky V, Kane GC, Borlaug BA (2015) Differential hemodynamic effects of exercise and volume expansion in people with and without heart failure. Circ Heart Fail 8: 41-48. [Crossref]

12. Sugiura Kojima M, Noda A, Miyata S, Kojima J, Hara Y, et al. (2015) The Effect of Habitual Physical Training on Left Ventricular Function During Exercise Assessed by Three-Dimensional Echocardiography. Echocardiography 32: 1670-1675.

13. Milia R, Roberto S, Mulliri G, Loi A, Marcelli M, et al. (2015) Effect of aging on hemodynamic response to metaboreflex activation. Eur J Appl Physiol 115: 1693-1703. [Crossref]

14. Munch GD, Svendsen JH, Damsgaard R, Secher NH, Gonzalez-Alonso J, et al. (2014) Maximal heart rate does not limit cardiovascular capacity in healthy humans: insight from right atrial pacing during maximal exercise. J Physiol 592: 377-390.

15. [No authors listed] (2014) American College of Cardiology/American Heart Association release new guideline for assessing cardiovascular risk in adults. Eur Heart J35: 132-133. [Crossref]

16. Joyner MJ, Casey DP (2015) Regulation of Increased Blood Flow (Hyperemia) to Muscles During Exercise: A Hierarchy of Competing Physiological Needs. Physiol Rev 95: 549-601.

17. Simoes RP, Bonjorno JC, Beltrame T, Catai AM, Arena R, Borghi-Silva A (2013) Slower heart rate and oxygen consumption kinetic responses in the on- and off-transient during a discontinuous incremental exercise: effects of aging. Braz J Phys Ther 17: 69-76. 
18. Carrick-Ranson G, Hastings JL, Bhella PS, Shibata S, Fujimoto N, et al. (2013) The effect of age-related differences in body size and composition on cardiovascular determinants of VO2max. J Gerontol A Biol Sci Med Sci 68: 608-616. [Crossref]

19. Jain M, Nkonde C, Lin BA, Walker A, Wackers FJ (2011) $85 \%$ of maximal agepredicted heart rate is not a valid endpoint for exercise treadmill testing. $\mathrm{J} \mathrm{Nucl}$ Cardiol 18: 1026-1035. [Crossref]

20. Pinkstaff S, Peberdy MA, Kontos MC, Finucane S, Arena R (2010) Quantifying exertion level during exercise stress testing using percentage of age-predicted maximal heart rate, rate pressure product, and perceived exertion.Mayo Clin Proc 85: 1095 1100. [Crossref]

21. Golubic R, Martin KR, Ekelund U, Hardy R, Kuh D, et al. (2014) Levels of physical activity among a nationally representative sample of people in early old age: results of objective and self-reported assessments. Int J Behav Nutr Phys Act 11: 58. [Crossref]

22. Wilson MG, Ellison GM, Cable NT (2015) Basic science behind the cardiovascular benefits of exercise. Heart 101: 758-765. [Crossref]

23. Johnson A, Mohajer-Esfahani M (2014) Exploring hemodynamics: a review of current and emerging noninvasive monitoring techniques. Crit Care Nurs Clin North Am 26: 357-375. [Crossref]

24. Carrick-Ranson G, Hastings JL, Bhella PS, Fujimoto N, Shibata S, et al. (2014) The effect of lifelong exercise dose on cardiovascular function during exercise. $J$ Appl Physiol (1985) 116: 736-745. [Crossref]

25. Rivera-Brown AM, Frontera WR (2012) Principles of exercise physiology: responses to acute exercise and long-term adaptations to training. PM $R$ 4: 797-804. [Crossref]

26. Carrick-Ranson G, Doughty RN, Whalley GA, Walsh HJ, Gamble GD, et al. (2012) The larger exercise stroke volume in endurance-trained men does not result from increased left ventricular early or late inflow or tissue velocities. Acta Physiol (Oxf) 205: 520531. [Crossref]

27. Bearden SE, Moffatt RJ (2001) VO2 and heart rate kinetics in cycling: transitions from an elevated baseline. J Appl Physiol (1985) 90: 2081-2087. [Crossref]

28. Carrick D, Berry C (2013) Prognostic importance of myocardial infarct characteristics. Eur Heart J Cardiovasc Imaging 14: 313-315. [Crossref]

29. Fletcher GF, Ades PA, Kligfield P, Arena R, Balady GJ, et al. (2013) Exercise standards for testing and training: a scientific statement from the American Heart Association. Circulation 128: 873-934. [Crossref]

30. Syme AN, Blanchard BE, Guidry MA, Taylor AW, Vanheest JL, et al. (2006) Peak systolic blood pressure on a graded maximal exercise test and the blood pressure response to an acute bout of submaximal exercise. Am J Cardiol 98: 938-943. [Crossref]

31. Halliwill JR, Buck TM, Lacewell AN, Romero SA (2013) Postexercise hypotension and sustained postexercise vasodilatation: what happens after we exercise? Exp Physiol 98: 7-18. [Crossref]

32. Amann M, Venturelli M, Ives SJ, Morgan DE, Gmelch B, et al. (2014) Group III/ IV muscle afferents impair limb blood in patients with chronic heart failure. Int $J$ Cardiol 174: 368-375. [Crossref]

33. Montero D, Diaz-Ca $\tilde{ \pm} \pm$ estro C, Lundby C (2015) Endurance Training and VËTMO2max Role of Maximal Cardiac Output and Oxygen Extraction. Med Sci Sports Exerc 47: 2024-2033. [Crossref]

34. Vallecilla C, Khiabani RH, Trusty P, Sandoval N, Fogel M, et al. (2015) Exercise capacity in the Bidirectional Glenn physiology: Coupling cardiac index, ventricular function and oxygen extraction ratio. J Biomech 48: 1997-2004.

35. Bassett DR Jr, Howley ET (1997) Maximal oxygen uptake: "classical" versus "contemporary" viewpoints. Med Sci Sports Exerc 29: 591-603. [Crossref]

36. Zilinski JL, Contursi ME, Isaacs SK, Deluca JR, Lewis GD, et al. (2015) Myocardial adaptations to recreational marathon training among middle-aged men. Circ Cardiovasc Imaging 8: e002487. [Crossref]

37. Castello-Simoes V, Minatel V, Karsten M, et al. (2015) Circulatory and Ventilatory Power: Characterization in Patients with Coronary Artery Disease. Arq Bras Cardiol.

38. Myers J, Arena R, Franklin B, Pina I, Kraus WE, et al. (2009) Recommendations for clinical exercise laboratories: a scientific statement from the american heart association. Circulation 119: 3144-3161.

39. Myers J, Voodi L, Umann T, Froelicher VF (2000) A survey of exercise testing: methods, utilization, interpretation, and safety in the VAHCS. J Cardiopulm Rehabil 20: 251258. [Crossref]

40. Kurl S, Jae SY, Kauhanen J, Ronkainen K, Rauramaa R, et al. (2015) Exercise cardiac power and the risk of sudden cardiac death in a long-term prospective study. Int $J$ Cardiol 181: 155-159. [Crossref]

41. Harmon KG, Zigman M, Drezner JA (2015) The effectiveness of screening history, physical exam, and ECG to detect potentially lethal cardiac disorders in athletes: a systematic review/meta-analysis. J Electrocardiol 48: 329-338. [Crossref]

42. Thompson PD, Arena R, Riebe D, Pescatello LS (2013) American College of Sports M. ACSM's new preparticipation health screening recommendations from ACSM's guidelines for exercise testing and prescription, ninth edition. Curr Sports Med Rep 12: $215-217$.

43. Fihn SD, Blankenship JC, Alexander KP, et al. (2014) Focused update of the guideline for the diagnosis and management of patients with stable ischemic heart disease: a report of the American College of Cardiology/American Heart Association Task Force on Practice Guidelines, and Society of Thoracic Surgeons. J Thorac Cardiovasc Surg 149: e5-23.

44. Warth J, Desforges JF (1975) Determinants of intracellular $\mathrm{pH}$ in the erythrocyte. $\mathrm{Br} J$ Haematol 29: 369-372. [Crossref]

45. Medicine (2008) ACoS. ACSM's Resource Manual for Guidelines for Exercise Testing and Prescription. . Philadelphia, PA: Lippincott Williams \& Wilkins

46. Fihn SD, Gardin JM, Abrams J, et al. (2012) Guideline for the diagnosis and management of patients with stable ischemic heart disease: a report of the American College of Cardiology Foundation/American Heart Association Task Force on Practice Guidelines, and the American College of Physicians, American Association for Thoracic Surgery, Preventive Cardiovascular Nurses Association, Society for Cardiovascular Angiography and Interventions, and Society of Thoracic Surgeons. $J$ Am Coll Cardiol 60: e44-e164.

47. Hicks KA, Tcheng JE, Bozkurt B, et al. (2014) Key Data Elements and Definitions for Cardiovascular Endpoint Events in Clinical Trials: A Report of the American College of Cardiology/American Heart Association Task Force on Clinical Data Standards (Writing Committee to Develop Cardiovascular Endpoints Data Standards). J Am Coll Cardiol.

48. Duvall WL, Savino JA, Levine EJ, Hermann LK, Croft LB, et al. (2015) Prospective evaluation of a new protocol for the provisional use of perfusion imaging with exercise stress testing. Eur J Nucl Med Mol Imaging 42: 305-316. [Crossref]

49. Nilsson G, Mooe T, Stenlund H, Samuelsson E (2014) Diagnostic characteristics and prognoses of primary-care patients referred for clinical exercise testing: a prospective observational study. BMC Fam Pract 15: 71.

50. Higgins JP, Higgins JA (2007) Electrocardiographic exercise stress testing: an update beyond the ST segment. Int J Cardiol 116: 285-299. [Crossref]

51. Henri C, Piérard LA, Lancellotti P, Mongeon FP, Pibarot P, et al. (2014) Exercise testing and stress imaging in valvular heart disease. Can J Cardiol 30: 1012-1026. [Crossref]

52. American Association of C, Pulmonary R, American College of Cardiology F, et al. (2010) Update: Performance Measures on Cardiac Rehabilitation for Referral to Cardiac Rehabilitation/Secondary Prevention Services Endorsed by the American College of Chest Physicians, the American College of Sports Medicine, the American Physical Therapy Association, the Canadian Association of Cardiac Rehabilitation, the Clinical Exercise Physiology Association, the European Association for Cardiovascular Prevention and Rehabilitation, the Inter-American Heart Foundation, the National Association of Clinical Nurse Specialists, the Preventive Cardiovascular Nurse Association, and the Society of Thoracic Surgeons. J Am Coll Cardiol 56: 1159-1167.

53. Courand PY, Grandjean A, Charles P, Paget V, Khettab F, et al. (2015) R Wave in aVL Lead is a Robust Index of Left Ventricular Hypertrophy: A Cardiac MRI Study. Am J Hypertens 28: 1038-1048. [Crossref]

54. Cools FJ, van Twembeke RR, Backers J, Verpooten GA (2003) Stability of far field R wave signals in different conditions. Europace 5: 175-183. [Crossref]

55. Fotuhi P, Combs W, Condie C, Theres H, Schneider T, et al. (2001) R-wave detection by subcutaneous ECG. Possible use for analyzing R-R variability. Ann Noninvasive Electrocardiol 6: 18-23. [Crossref]

56. Hurst JW (2008) To simply identify "up or down" displacement of the ST segment in the electrocardiogram can lead to serious errors. J Electrocardiol 41: 436-437. [Crossref]

57. Hanna EB, Glancy DL (2015) ST-segment elevation: Differential diagnosis, caveats. Cleve Clin J Med 82: 373-384. [Crossref]

58. Karakulak UN, Okutucu S, Åžahiner L, Maharjan N, Aladag E, et al. (2015) Assessment of cardiac autonomic nervous system involvement in systemic sclerosis via exercise heart rate recovery. Med Princ Pract 24: 17-22. [Crossref] 
59. Lim HC, Salandanan EA, Phillips R, Tan JG, Hezan MA (2015) Inter-rater reliability of J-point location and measurement of the magnitude of ST segment elevation at the J-point on ECGs of STEMI patients by emergency department doctors. Emerg Med J 32: 809-812.

60. Hodnesdal C, Prestgaard E, Erikssen G, Gjesdal K, Kjeldsen SE, et al. (2013) Rapidly upsloping ST-segment on exercise ECG: a marker of reduced coronary heart disease mortality risk. Eur J Prev Cardiol 20: 541-548. [Crossref]

61. Goebel M, Bledsoe J, Orford JL, Mattu A, Brady WJ (2014) A new ST-segment elevation myocardial infarction equivalent pattern? Prominent $\mathrm{T}$ wave and J-poin depression in the precordial leads associated with ST-segment elevation in lead aVr. Am J Emerg Med 32: 287 e5-8.

62. Maile MD, Engoren MC, Tremper KK, Tremper TT, Jewell ES, et al. (2016) Variability of Automated Intraoperative ST Segment Values Predicts Postoperative Troponin Elevation. Anesth Analg 122: 608-615. [Crossref]

63. Mitu O, Mitu F, Leon MM, Roca M, Graur M (2015) ST segment depression in asymptomatic male patient with normal coronary arteries. Rev Med Chir Soc Med Nat Iasi 119: 101-106. [Crossref]

64. Tjandrawidjaja MC, Fu Y, Westerhout CM, White HD, Todaro TG, et al. (2010) Resolution of ST-segment depression: A new prognostic marker in ST-segment elevation myocardial infarction. Eur Heart J 31: 573-581. [Crossref]

65. Misumida N, Kobayashi A, Fox JT, Hanon S, Schweitzer P, Kanei Y (2015) Predictive Value of ST-Segment Elevation in Lead aVR for Left Main and/or Three-Vessel Disease in Non-ST-Segment Elevation Myocardial Infarction. Ann Noninvasive Electrocardiol.

66. Pósa A, Szabó R, Kupai K, Baráth Z, Szalai Z, et al. (2015) Cardioprotective effects of voluntary exercise in a rat model: role of matrix metalloproteinase-2. Oxid Med Cell Longev 2015: 876805. [Crossref]

67. Kaluzay J, Vandenberghe K, Fontaine D, Ganame J, Anné W, et al. (2005) Importance of measurements at or after the J-point for evaluation of ST-segment deviation and resolution during treatment for acute myocardial infarction.Int J Cardiol 98: 431-437. [Crossref]

68. Hänninen H, Takala P, Mäkijärvi M, Korhonen P, Oikarinen L, et al. (2001) ST-segment level and slope in exercise-induced myocardial ischemia evaluated with body surface potential mapping. Am J Cardiol 88: 1152-1156.

69. Lachterman B, Lehmann KG, Abrahamson D, Froelicher VF (1990) "Recovery only" ST-segment depression and the predictive accuracy of the exercise test. Ann Intern Med 112: 11-16. [Crossref]

70. Lanza GA, Mustilli M, Sestito A, Infusino F, Sgueglia GA, et al. (2004) Diagnostic and prognostic value of ST segment depression limited to the recovery phase of exercise stress test. Heart 90: 1417-1421. [Crossref]

71. Desai MY, Bhonsale A, Patel P, et al. (2014) Exercise echocardiography in asymptomatic HCM: exercise capacity, and not LV outflow tract gradient predicts longterm outcomes. JACC Cardiovasc Imaging 7: 26-36.

72. Scalone G, Brugaletta S, Gomez-Monterrosas O, Otsuki S, Sabate M (2015) STsegment elevation myocardial infarction - ideal scenario for bioresorbable vascular scaffold implantation? Circ J 79: 263-270.

73. Li J, Li X, Wang Q, Hu S, Wang Y, et al. (2015) ST-segment elevation myocardial infarction in China from 2001 to 2011 (the China PEACE-Retrospective Acute Myocardial Infarction Study): a retrospective analysis of hospital data. Lancet 385: 441-451.

74. Desai MY, Crugnale S, Mondeau J, Helin K, Mannting F (2002) Slow upsloping STsegment depression during exercise: does it really signify a positive stress test? $\mathrm{Am}$ Heart $J$ 143: 482-487. [Crossref]

75. Garber AM, Mentz RJ, Al-Khalidi HR, et al.(2015) Clinical predictors and outcomes of patients with left ventricular thrombus following ST-segment elevation myocardial infarction. J Thromb Thrombolysis.

76. Liang M, Kajiya T, Chan MY, Tay E, Lee CH, et al. (2015) High-grade culprit lesions are a common cause of ST-segment elevation myocardial infarction. Singapore Med J 56: 334-338. [Crossref]

77. Lanzer P, Widimský P (2015) Ischaemic stroke and ST-segment elevation myocardial infarction: fast-track single-stop approach. Eur Heart J 36: 2348-2355. [Crossref]

78. Uthamalingam S, Zheng H, Leavitt M, Pomerantsev E, Ahmado I, et al. (2011) Exerciseinduced ST-segment elevation in ECG lead aVR is a useful indicator of significant left main or ostial LAD coronary artery stenosis. JACC Cardiovasc Imaging 4: 176-186. [Crossref]
79. Masrur S, Memon S, Thompson PD (2015) Brugada syndrome, exercise, and exercise testing. Clin Cardiol 38: 323-326. [Crossref]

80. Dauerman HL, Bates ER, Kontos MC, et al. (2015) Nationwide Analysis of Patients With ST-Segment-Elevation Myocardial Infarction Transferred for Primary Percutaneous Intervention: Findings From the American Heart Association Mission: Lifeline Program. Circ Cardiovasc Interv.

81. Ichiba T1 (2016) An unusual adverse event of acute urinary retention: ST-segmen elevation myocardial infarction. Am J Emerg Med 34: 347. [Crossref]

82. Becker S, Chisholm G, Maeng M (2013) Positive predictive value of clinically suspected ST-segment elevation myocardial infarction using angiographic verification Am J Cardiol 112: 923-927.

83. Bruce RA, Fisher LD, Pettinger M, Weiner DA, Chaitman BR (1988) ST segmen elevation with exercise: a marker for poor ventricular function and poor prognosis. Coronary Artery Surgery Study (CASS) confirmation of Seattle Heart Watch results. Circulation 77: 897-905.

84. Orsini E, Lattanzi F, Reisenhofer B, Tartarini G (2001) Time-domain analysis of exercise-induced ST-segment elevation in Q-wave myocardial infarction: a useful tool for the screening of myocardial viability. Ital Heart J 2: 529-538. [Crossref]

85. Duncan RF, Dundon BK, Nelson AJ, et al.(2014) A study of the 16-Segment Regiona Wall Motion Scoring Index and biplane Simpson's rule for the calculation of left ventricular ejection fraction: a comparison with cardiac magnetic resonance imaging. Echocardiography 28: 597-604.

86. Sunbul M, Erdogan O, Sari I (2014) Asymptomatic ST segment elevation in the recovery phase of the exercise stress test due to slow coronary flow. Postepy Kardiol Interwencyjnej 10: 53-56. [Crossref]

87. Ibrahim M, Hasan R, Pitonak P (2013) Exercise-induced ST-segment elevation during the recovery phase of an exercise stress test. Exp Clin Cardiol 18: e92-94. [Crossref]

88. de Gregorio C, Saporito F, Andò G, Morabito G, Cerrito M, et al. (2011) Hyperventilation-induced ST segment elevation mimicking acute myocardial infarction in a comatose patient with tracheostomy. Int J Cardiol 149: e47-49. [Crossref]

89. Keller KB, Lemberg L (2004) Prinzmetal's angina. Am J Crit Care 13: 350-354 [Crossref]

90. Scardi S, Pivotti F, Pandullo C, Ceschia G, Salvi A (1988) Exercise-induced intermitten angina and ST-segment elevation in Prinzmetal's angina. Eur Heart $J$ 9: 102-105. [Crossref]

91. Beinart R, Matetzky S, Shechter M, Fefer P, Rozen E, et al. (2008) Stress-induced ST-segment elevation in patients without prior Q-wave myocardial infarction. $J$ Electrocardiol 41: 312-317. [Crossref]

92. D’Onofrio G, Safdar B, Lichtman JH, Strait KM, Dreyer RP, et al. (2015) Sex differences in reperfusion in young patients with ST-segment-elevation myocardial infarction: results from the VIRGO study. Circulation 131: 1324-1332.

93. Huang B, Wang X, Yang Y, et al. (2015) Association of Admission Glycaemia With High Grade Atrioventricular Block in ST-Segment Elevation Myocardial Infarction Undergoing Reperfusion Therapy: An Observational Study. Medicine (Baltimore) 94 e1167.

94. Lalonde F, Poirier P, Sylvestre MP, Arvisais D, Curnier D (2015) Exercise-induced ischemic preconditioning detected by sequential exercise stress tests: a metaanalysis. Eur J Prev Cardiol 22: 100-112. [Crossref]

95. Mitu O, Roca M, Leon MM, Mitu F (2014) Predictive value of a positive exercise stress testing and correlations with cardiovascular risk factors. Rev Med Chir Soc Med Nat Iasi 118: 57-62. [Crossref]

96. Hochgruber T, Reichlin T, Wasila M, Vogler E, Twerenbold R, et al. (2014) Nove insights into the pathophysiology of different forms of stress testing. Clin Biochem 47: 338-343. [Crossref]

97. Izzo P, Macchi A, De Gennaro L, Gaglione A, Di Biase M, et al. (2012) Recurren angina after coronary angioplasty: mechanisms, diagnostic and therapeutic options. Eur Heart J Acute Cardiovasc Care 1: 158-169.

98. Hoyt WJ Jr, Ardoin KB, Cannon BC, Snyder CS (2015) T-wave reversion in pediatric patients during exercise stress testing. Congenit Heart Dis 10: E68-72. [Crossref]

99. Qaseem A, Fihn SD, Williams S, et al. (2015) Diagnosis of stable ischemic heart disease: summary of a clinical practice guideline from the American College of Physicians/American College of Cardiology Foundation/American Heart Association/ American Association for Thoracic Surgery/Preventive Cardiovascular Nurses Association/Society of Thoracic Surgeons. Ann Intern Med 157: 729-734. 
100. Summary for patients (2012) Diagnosis of stable ischemic heart disease: recommendations from the American College of Physicians, American College of Cardiology Foundation, American Heart Association, American Association for Thoracic Surgery, Preventive Cardiovascular Nurses Association, and Society of Thoracic Surgeons. Ann Intern Med 157: I-42.

101. Dhoble A, Lahr BD, Allison TG, Kopecky SL (2014) Cardiopulmonary fitness and heart rate recovery as predictors of mortality in a referral population. $J$ Am Heart Assoc 3: e000559. [Crossref]

102. Figueras J, Domingo E, Ferreira I, Bellera N, Lidon RM, Garcia-Dorado D (2012) Angina without significant coronary stenosis of non vasospastic origin. Clinical profile and long-term follow-up of patients with vs patients without stress induced ST segment depression. Int J Cardiol 161: 53-55.

103. Sacco RL, Adams R, Albers G, Alberts MJ, Benavente O, et al. (2006) Guidelines for prevention of stroke in patients with ischemic stroke or transient ischemic attack: a statement for healthcare professionals from the American Heart Association/American Stroke Association Council on Stroke: co-sponsored by the Council on Cardiovascular Radiology and Intervention: the American Academy of Neurology affirms the value of this guideline. Circulation 113: e409-449. [Crossref]

104. Ferro A, Petretta M, Acampa W, Fiumara G, Daniele S, et al. (2013) Post-stress left ventricular ejection fraction drop in patients with diabetes: a gated myocardial perfusion imaging study. BMC Cardiovasc Disord 13: 99.

105. Gitt A, Jannowitz C, Karoff M, Karmann B, Horack M, et al. (2012) Treatment patterns and risk factor control in patients with and without metabolic syndrome in cardiac rehabilitation. Vasc Health Risk Manag 8: 265-274.

106. Palaniswamy C, Aronow WS (2011) Treatment of stable angina pectoris. $A m J$ Ther 18: e138-152. [Crossref]

107. Kim MK, Baek KH, Song KH, Kwon HS, Lee JM, et al. (2011) Exercise treadmill tes in detecting asymptomatic coronary artery disease in type 2 diabetes mellitus. Diabetes Metab J 35: 34-40. [Crossref]

108. Abidov A, Rozanski A, Hachamovitch R, Hayes SW, Aboul-Enein F, et al. (2005) Prognostic significance of dyspnea in patients referred for cardiac stress testing. $N$ Engl J Med 353: 1889-1898. [Crossref]

109. Chase P, Arena R, Myers J, Abella J, Peberdy MA, et al. (2008) Relation of the prognostic value of ventilatory efficiency to body mass index in patients with heart failure. Am J Cardiol 101: 348-352. [Crossref]

110. Gibbons RJ, Balady GJ, Bricker JT, et al. (2002) Guideline update for exercise testing: summary article. A report of the American College of Cardiology/American Heart Association Task Force on Practice Guidelines (Committee to Update the 1997 Exercise Testing Guidelines). J Am Coll Cardiol 40: 1531-1540.

111. Tavel ME (2001) Stress testing in cardiac evaluation: current concepts with emphasis on the ECG. Chest 119: 907-925. [Crossref]

112. Tavel ME (1996) The appearance of gallop rhythm after exercise stress testing. Clin Cardiol 19: 887-891. [Crossref]

113. Tavel ME, Shaar C (1999) Relation between the electrocardiographic stress test and degree and location of myocardial ischemia. Am J Cardiol 84: 119-124. [Crossref]

114. Gibbons RJ, Balady GJ, Bricker JT, et al. (1883) Guideline update for exercise testing: summary article: a report of the American College of Cardiology/American Heart Association Task Force on Practice Guidelines (Committee to Update the 1997 Exercise Testing Guidelines). Circulation 106:1883-

115. Majidi M, KosinskiAS, Al-Khatib SM, Smolders L, Cristea E, et al. (2015) Implications of ventricular arrhythmia "bursts" with normal epicardial flow, myocardial blush, and ST-segment recovery in anterior ST-elevation myocardial infarction reperfusion: a biosignature of direct myocellular injury "downstream of downstream". Eur Heart $J$ Acute Cardiovasc Care 4: 51-59. [Crossref]

116. Detrano R, Gianrossi R, Mulvihill D, Lehmann K, Dubach P, et al. (1989) Exerciseinduced ST segment depression in the diagnosis of multivessel coronary disease: a meta analysis. J Am Coll Cardiol 14: 1501-1508. [Crossref]

117. Witte KK, Thackray SD, Nikitin NP, Cleland JG, Clark AL (2003) Pattern of ventilation during exercise in chronic heart failure. Heart 89: 610-614.

118. Lipinski M, Froelicher V, Atwood E, Tseitlin A, Franklin B, et al. (2002) Comparison of treadmill scores with physician estimates of diagnosis and prognosis in patients with coronary artery disease. Am Heart $J$ 143: 650-658. [Crossref]

119. Houghton AR, Harrison M, Cowley AJ, Hampton JR (2002) Assessing exercise capacity, quality of life and haemodynamics in heart failure: do the tests tell us the same thing? Eur J Heart Fail 4: 289-295. [Crossref]
120. Froelicher VF (2001) Exercise testing in the new millennium. Prim Care 28: 1-4 ,v. [Crossref]

121. Bigi R, Desideri A, Rambaldi R, Cortigiani L, Sponzilli C, et al. (2001) Angiographic and prognostic correlates of cardiac output by cardiopulmonary exercise testing in patients with anterior myocardial infarction. Chest 120: 825-833.

122. Moyers BS, Goldschlager N (2012) ST-segment elevation: alert the catheterization laboratory? Arch Intern Med 172: 1439-1441. [Crossref]

123. Kligfield P, Ameisen O, Okin PM (1989) Heart rate adjustment of ST segment depression for improved detection of coronary artery disease. Circulation 79: 245255. [Crossref]

124. Myers J, FroelicherVF (1993) Exercise testing. Procedures and implementation. Cardiol Clin 11: 199-213. [Crossref]

125. Froelicher VF, Duarte GM, Oakes DF, Klein J, Dubach PA, et al. (1988) The prognostic value of the exercise test. Dis Mon 34: 677-735. [Crossref]

126. Zou KH, O'Malley AJ, Mauri L (2007) Receiver-operating characteristic analysis for evaluating diagnostic tests and predictive models. Circulation 115: 654-657.

127. Pinkstaff SO (2015) Much potential but many unanswered questions for high-intensity intermittent exercise training for patients with heart failure. Heart Fail Clin 11: 133148. [Crossref]

128. Arena R, Myers J, Abella J, Pinkstaff S, Brubaker P, et al. (2011) Cardiopulmonary exercise testing is equally prognostic in young, middle-aged and older individuals diagnosed with heart failure. Int J Cardiol 151: 278-283.

129. Duncker DJ, Bache RJ (2008) Regulation of coronary blood flow during exercise. Physiol Rev 88: 1009-1086. [Crossref]

130. Pigozzi F, Spataro A, Alabiso A, Parisi A, Rizzo M, et al. (2005) Role of exercise stress test in master athletes. Br J Sports Med 39: 527-531. [Crossref]

131. Sugrue A (2015) New electrocardiographic criteria to differentiate the type-2 Brugada pattern from electrocardiogram of healthy athletes with r'-wave in leads V1/V2. Europace 17: 504-505.

132. Coustet B, Lhuissier FJ, Vincent R, Richalet JP2 (2015) Electrocardiographic changes during exercise in acute hypoxia and susceptibility to severe high-altitude illnesses. Circulation 131: 786-794. [Crossref]

133. Al-Mallah M, Dajani K, Hudson M, Iyengar H, Gutierrez N, et al. (2005) Long-term outcomes based on time-to-angioplasty in patients admitted with non-ST-segment elevation acute coronary syndromes. J Invasive Cardiol 17: 251-255.

134. Noël M, Jobin J, Marcoux A, Poirier P, Dagenais G, et al. (2010) Comparison of myocardial ischemia on the ergocycle versus the treadmill in patients with coronary heart disease. Am J Cardiol 105: 633-639. [Crossref]

135. Noel N, Naheed Z (2013) Hypertrophic cardiomyopathy: role of current recommendations by the american heart association for infective endocarditis. Pediatr Cardiol 34:709-11.

136. Zaidi A, Sheikh N, Jongman JK, et al. (2015) Clinical Differentiation Between Physiological Remodeling and Arrhythmogenic Right Ventricular Cardiomyopathy in Athletes With Marked Electrocardiographic Repolarization Anomalies. J Am Coll Cardiol 65:2702-11.

137. Kligfield P, Badilini F, Rowlandson I, et al. (2014) Comparison of automated measurements of electrocardiographic intervals and durations by computer-based algorithms of digital electrocardiographs. Am Heart J 167:150-9 e1.

138. Maron BJ, Friedman RA, Kligfield P, et al. (2014) Assessment of the 12-lead electrocardiogram as a screening test for detection of cardiovascular disease in healthy general populations of young people (12-25 years of age): a scientific statement from the American Heart Association and the American College of Cardiology. J Am Coll Cardiol 64:1479-514.

139. Kligfield P, Green CL (2012) The Cardiac Safety Research Consortium ECG database. J Electrocardiol 45: 690-692. [Crossref]

140. Kligfield P, Hancock EW, Helfenbein ED, Dawson EJ, Cook MA, et al. (2006) Relation of QT interval measurements to evolving automated algorithms from different manufacturers of electrocardiographs. Am J Cardiol 98: 88-92. [Crossref]

141. Kligfield P (2006) Rethinking the exercise electrocardiogram. Ann Noninvasive Electrocardiol 11: 99-101. [Crossref]

142. Kligfield P, Lauer MS (2006) Exercise electrocardiogram testing: beyond the ST segment. Circulation 114: 2070-2082. [Crossref] 
143. Detry JM (1972) Exercise testing and training in coronary heart disease. Rev Inst Hyg Mines (Hasselt) 27: 5-82. [Crossref]

144. Detry JM, Piette F, Brasseur LA (1970) Hemodynamic determinants of exercise STsegment depression in coronary patients. Circulation 42: 593-599. [Crossref]

145. Reibis R, Völler H, Gitt A, Jannowitz C, Halle M, et al. (2014) Management of patients with ST-segment elevation or non-ST-segment elevation acute coronary syndromes in cardiac rehabilitation centers. Clin Cardiol 37: 213-221. [Crossref]

146. Lee MF, Chen WS, Fu TC, et al. (2012) Non-invasive cardiac index monitoring during cardiopulmonary functional testing provides additional prognostic value in patients after acute heart failure. Int Heart J 53:364-9.

147. Myers J, Gujja P, Neelagaru S, Hsu L, Burkhoff D (2009) Quantification of the impaired cardiac output response to exercise in heart failure: application of a noninvasive device. J Sports Sci Med 8: 344-351. [Crossref]

148. Myers J, Gujja P, Neelagaru S, Hsu L, Vittorio T, et al. (2009) End-tidal CO2 pressure and cardiac performance during exercise in heart failure. Med Sci Sports Exerc 41: 19-25. [Crossref]

149. Akima T, Takase B, Kosuda S, Ohsuzu F, Kawai T, et al. (2007) Systemic peripheral vascular resistance as a determinant of functional cardiac reserve in response to exercise in patients with heart disease. Angiology 58: 463-471.

150. Kligfield P, Gettes LS, Bailey JJ, et al. (2007) Recommendations for the standardization and interpretation of the electrocardiogram: part I: the electrocardiogram and its technology a scientific statement from the American Heart Association Electrocardiography and Arrhythmias Committee, Council on Clinical Cardiology; the American College of Cardiology Foundation; and the Heart Rhythm Society endorsed by the International Society for Computerized Electrocardiology. $J$ Am Coll Cardiol 49:1109-27.

151. Kligfield P, Lax KG, Okin PM (1995) QTc behavior during treadmill exercise as a function of the underlying QT-heart rate relationship. J Electrocardiol 28 Suppl: 206 210. [Crossref]

152. Okin PM, Kligfield P (1995) Heart rate adjustment of ST segment depression and performance of the exercise electrocardiogram: a critical evaluation. $J$ Am Coll Cardiol 25: 1726-1735. [Crossref]

153. Halub ME, Sidwell RA (2015) Cardiac risk stratification and protection. Surg Clin North Am 95: 217-235. [Crossref]

154. Fihn SD, Blankenship JC, Alexander KP, et al. (2014) ACC/AHA/AATS/PCNA/SCAI/ STS focused update of the guideline for the diagnosis and management of patients with stable ischemic heart disease: a report of the American College of Cardiology/ American Heart Association Task Force on Practice Guidelines, and the American Association for Thoracic Surgery, Preventive Cardiovascular Nurses Association, Society for Cardiovascular Angiography and Interventions, and Society of Thoracic Surgeons. J Am Coll Cardiol 64:1929-49.

155. Eckel RH, Jakicic JM, Ard JD, et al. (2013) AHA/ACC guideline on lifestyle management to reduce cardiovascular risk: a report of the American College of Cardiology/American Heart Association Task Force on Practice Guidelines. Circulation 129:S76-99.

156. Eagle KA, Guyton RA, Davidoff R, et al. (1999) ACC/AHA Guidelines for Coronary Artery Bypass Graft Surgery: A Report of the American College of Cardiology/ American Heart Association Task Force on Practice Guidelines (Committee to Revise the 1991 Guidelines for Coronary Artery Bypass Graft Surgery). American College of Cardiology/American Heart Association. J Am Coll Cardiol 34:1262-347.

157. Lauer M, Froelicher ES, Williams M, Kligfield P (2005) Exercise testing in asymptomatic adults: a statement for professionals from the American Hear Association Council on Clinical Cardiology, Subcommittee on Exercise, Cardiac Rehabilitation, and Prevention. Circulation 112: 771-776.

158. Gorodeski EZ, Ishwaran H, Blackstone EH, Lauer MS (2009) Quantitative electrocardiographic measures and long-term mortality in exercise test patients with clinically normal resting electrocardiograms. Am Heart $J$ 158: 61-70. [Crossref]

159. Arena R, Myers J, Guazzi M (2011) Cardiopulmonary exercise testing is a core assessment for patients with heart failure. Congest Heart Fail 17: 115-119. [Crossref]

160. Sandesara PB, Lambert CT, Gordon NF, Fletcher GF, Franklin BA, et al. (2015) Cardiac rehabilitation and risk reduction: time to "rebrand and reinvigorate". $J \mathrm{Am}$ Coll Cardiol 65: 389-395. [Crossref]

161. Saglam M, Vardar-Yagli N, Savci S, et al. (2014) Functional capacity, physical activity, and quality of life in hypoxemic patients with chronic obstructive pulmonary disease. Int J Chron Obstruct Pulmon Dis 10:423-8.
162. Kosmala W, Jellis CL, Marwick TH (2015) Exercise limitation associated with asymptomatic left ventricular impairment: analogy with stage B heart failure. $J \mathrm{Am}$ Coll Cardiol 65: 257-266. [Crossref]

163. Finocchiaro G, Haddad F, Knowles JW, Caleshu C, Pavlovic A, et al. (2015) Cardiopulmonary responses and prognosis in hypertrophic cardiomyopathy: a potential role for comprehensive noninvasive hemodynamic assessment. JACC Heart Fail 3: 408-418. [Crossref]

164. Rached F, Lhomme M, Camont L, et al. (2015) Defective functionality of small, dense HDL3 subpopulations in ST segment elevation myocardial infarction: Relevance of enrichment in lysophosphatidylcholine, phosphatidic acid and serum amyloid A. Biochim Biophys Acta 1851:1254-61.

165. Arena R, Cahalin LP (2014) Evaluation of cardiorespiratory fitness and respiratory muscle function in the obese population. Prog Cardiovasc Dis 56: 457-464. [Crossref]

166. Bourque JM, Holland BH, Watson DD, Beller GA (2009) Achieving an exercise workload of $>$ or $=10$ metabolic equivalents predicts a very low risk of inducible ischemia: does myocardial perfusion imaging have a role? J Am Coll Cardiol 54: 538545. [Crossref]

167. DeFina LF, Haskell WL, Willis BL, Barlow CE, Finley CE, et al. (2015) Physical activity versus cardiorespiratory fitness: two (partly) distinct components of cardiovascular health? Prog Cardiovasc Dis 57: 324-329. [Crossref]

168. Hagnäs MJ, Kurl S, Rauramaa R, Lakka TA, Mäkikallio TH, et al. (2015) The value of cardiorespiratory fitness and exercise-induced ST segment depression in predicting death from coronary heart disease. Int J Cardiol 196: 31-33. [Crossref]

169. Laukkanen JA, Mäkikallio TH, Rauramaa R, Kiviniemi V, Ronkainen K, et al. (2010) Cardiorespiratory fitness is related to the risk of sudden cardiac death: a populationbased follow-up study. J Am Coll Cardiol 56: 1476-1483. [Crossref]

170. Kitta Y, Obata JE, Nakamura T, Hirano M, Kodama Y, et al. (2009) Persistent impairment of endothelial vasomotor function has a negative impact on outcome in patients with coronary artery disease. J Am Coll Cardiol 53: 323-330. [Crossref]

171. Kodama S, Saito K, Tanaka S, Maki M, Yachi Y, et al. (2009) Cardiorespiratory fitness as a quantitative predictor of all-cause mortality and cardiovascular events in healthy men and women: a meta-analysis. JAMA 301: 2024-2035. [Crossref]

172. Dekleva M, Dungen HD, Gelbrich G, et al. (2012) Beta blockers therapy is associated with improved left ventricular systolic function and sustained exercise capacity in elderly patients with heart failure. CIBIS-ELD sub-study. Aging Clin Exp Res 24: $675-81$.

173. Hosch O, Sohns JM, Nguyen TT, et al. (2014) The total right/left-volume index: a new and simplified cardiac magnetic resonance measure to evaluate the severity of Ebstein anomaly of the tricuspid valve: a comparison with heart failure markers from various modalities. Circ Cardiovasc Imaging 7:601-9.

174. Chen MS, Blackstone EH, Pothier CE, Lauer MS (2004) Heart rate recovery and impact of myocardial revascularization on long-term mortality. Circulation 110: 28512857. [Crossref]

175. Sharma K, Kohli P, Gulati M (2012) An update on exercise stress testing. Curr Probl Cardiol 37: 177-202. [Crossref]

176. Sydó N, Abdelmoneim SS, Mulvagh SL, Merkely B, Gulati M, et al. (2014) Relationship between exercise heart rate and age in men vs women. Mayo Clin Proc 89: 1664-1672. [Crossref]

177. Mieres JH, Gulati M, Bairey Merz N, Berman DS, Gerber TC, et al. (2014) Role of noninvasive testing in the clinical evaluation of women with suspected ischemic heart disease: a consensus statement from the American Heart Association. Circulation 130: 350-379.

178. Conraads VM, Pattyn N, De Maeyer C, Beckers PJ, Coeckelberghs E, et al. (2015) Aerobic interval training and continuous training equally improve aerobic exercise capacity in patients with coronary artery disease: the SAINTEX-CAD study. Int $J$ Cardiol 179: 203-210. [Crossref]

179. Pattyn N, Coeckelberghs E, Buys R, Cornelissen VA, Vanhees L (2014) Aerobic interval training vs. moderate continuous training in coronary artery disease patients: a systematic review and meta-analysis. Sports Med 44: 687-700.

180. Buys R, Van De Bruaene A, Müller J, Hager A, Khambadkone S, et al. (2013) Usefulness of cardiopulmonary exercise testing to predict the development of arterial hypertension in adult patients with repaired isolated coarctation of the aorta. Int $J$ Cardiol 168: 2037-2041. [Crossref]

181. Van De Bruaene A, De Meester P, Buys R, Vanhees L, Delcroix M, et al. (2013) Righ ventricular load and function during exercise in patients with open and closed atrial 
septal defect type secundum. Eur J Prev Cardiol 20: 597-604. [Crossref]

182. Guazzi M, Adams V, Conraads V, et al. (2012) EACPR/AHA Joint Scientific Statement Clinical recommendations for cardiopulmonary exercise testing data assessment in specific patient populations. Eur Heart J 33:2917-27.

183. Buys R, Cornelissen V, Van De Bruaene A, Stevens A, Coeckelberghs E, et al. (2011) Measures of exercise capacity in adults with congenital heart disease. Int $J$ Cardiol 153: 26-30. [Crossref]

184. Miller TD (2008) Exercise treadmill test: estimating cardiovascular prognosis. Cleve Clin J Med 75: 424-430. [Crossref]

185. Miller TD (2011) Stress testing: the case for the standard treadmill test. Curr Opin Cardiol 26: 363-369. [Crossref]

186. Killip T, Passamani E, Davis K (1985) Coronary artery surgery study (CASS): a randomized trial of coronary bypass surgery. Eight years follow-up and survival in patients with reduced ejection fraction. Circulation 72: V102-109.

187. Weinstein GS, Levin B (1985) The Coronary Artery Surgery Study (CASS). A critical appraisal. J Thorac Cardiovasc Surg 90: 541-548. [Crossref]

188. Kaiser GC, Davis KB, Fisher LD, Myers WO, Foster ED, et al. (1985) Survival following coronary artery bypass grafting in patients with severe angina pectoris (CASS). An observational study. J Thorac Cardiovasc Surg 89: 513-524. [Crossref]

189. Killip T (1985) The coronary artery surgery study (CASS)--a randomized trial and a registry. Z Kardiol 74 Suppl 6: 79-85. [Crossref]

190. King SB 3rd (1984) The coronary artery surgery study (CASS)--widely misinterpreted. J Med Assoc Ga 73: 251-252. [Crossref]

191. (1984) Myocardial infarction and mortality in the coronary artery surgery study (CASS) randomized trial. $N$ Engl J Med 310: 750-758. [Crossref]

192. Carvalho RS, Pires CM, Junqueira GC, Freitas D, Marchi-Alves LM1 (2015) Hypotensive response magnitude and duration in hypertensives: continuous and interval exercise. Arq Bras Cardiol 104: 234-241.

193. Sugawara J, Komine H, Miyazawa T, Imai T, Ogoh S (2015) Influence of single bout of aerobic exercise on aortic pulse pressure. Eur J Appl Physiol 115: 739-746. [Crossref]

194. Sun P, Yan H, Ranadive SM, Lane AD, Kappus RM, et al. (2015) Blood pressure changes following aerobic exercise in Caucasian and Chinese descendants. Int $J$ Sports Med 36: 189-196. [Crossref]

195. Sharman JE, LaGerche A (2015) Exercise blood pressure: clinical relevance and correct measurement. J Hum Hypertens 29: 351-358. [Crossref]

196. Hammermeister KE, DeRouen TA, Dodge HT, Zia M (1983) Prognostic and predictive value of exertional hypotension in suspected coronary heart disease. Am J Cardiol 51: 1261-1266. [Crossref]

197. Hakki AH, Munley BM, Hadjimiltiades S, Meissner MD, Iskandrian AS (1986) Determinants of abnormal blood pressure response to exercise in coronary artery disease. Am J Cardiol 57: 71-75. [Crossref]

198. Cunha FA, Midgley AW, Soares PP, Farinatti PT (2015) Postexercise hypotension after maximal short-term incremental exercise depends on exercise modality. Appl Physiol Nutr Metab 40: 605-614. [Crossref]

199. Deguchi K (2013) [Impaired exercise-induced blood pressure control in patients with Parkinson's disease and related disorders]. Rinsho Shinkeigaku 53: 1379-1381. [Crossref]

200. Dubach P, Froelicher VF, Klein J, Oakes D, Grover-McKay M, et al. (1988) Exercise-induced hypotension in a male population. Criteria, causes, and prognosis. Circulation 78: 1380-1387. [Crossref]

201. de Freitas Brito A, Coutinho de Oliveira CV, Brasileiro-Santos MD, Sarmento da Nobrega TK, et al. (2015) High-Intensity Resistance Exercise Promotes Postexercise Hypotension Greater Than Moderate Intensity and Affects Cardiac Autonomic Responses in Women Who Are Hypertensive. J Strength Cond Res 2015.

202. Cardoso GA, Silva AS, de Souza AA, Dos Santos MA, da Silva RS, et al. (2014) Influence of resistance training on blood pressure in patients with metabolic syndrome and menopause. J Hum Kinet 43: 87-95. [Crossref]

203. Dogan U, Duzenli MA, Ozdemir K, Gok H (2013) Blunted heart rate recovery is associated with exaggerated blood pressure response during exercise testing. Heart Vessels 28: 750-756. [Crossref]

204. Queiroz AC, Rezk CC, Teixeira L, Tinucci T, Mion D, et al. (2013) Gender influence on post-resistance exercise hypotension and hemodynamics. Int J Sports Med 34: 939944. [Crossref]
205. Pescatello LS, Franklin BA, Fagard R, Farquhar WB, Kelley GA, et al. (2004) American College of Sports Medicine position stand. Exercise and hypertension. Med Sci Sports Exerc 36: 533-553. [Crossref]

206. Harvey PJ, Morris BL, Kubo T, Picton PE, Su WS, et al. (2005) Hemodynamic aftereffects of acute dynamic exercise in sedentary normotensive postmenopausal women. J Hypertens 23: 285-292. [Crossref]

207. Carroll JF, Convertino VA, Pollock ML, Graves JE, Lowenthal DT (1995) Effect of 6 months of exercise training on cardiovascular responses to head-up tilt in the elderly. Clin Physiol 15: 13-25. [Crossref]

208. Suboc TB, Knabel D, Strath SJ, Dharmashankar K, Coulliard A, et al. (2016) Associations of Reducing Sedentary Time With Vascular Function and Insulin Sensitivity in Older Sedentary Adults. Am J Hypertens 29: 46-53. [Crossref]

209. Kokkinos P (2014) Cardiorespiratory fitness, exercise, and blood pressure. Hypertension 64: 1160-1164. [Crossref]

210. Verbrugge FH, Dupont M, Bertrand PB, Nijst P, Grieten L, et al. (2015) Pulmonary vascular response to exercise in symptomatic heart failure with reduced ejection fraction and pulmonary hypertension. Eur J Heart Fail 17: 320-328.

211. Liao LR, Ng GY, Jones AY, Pang MY (2015) Cardiovascular Stress Induced by Whole-Body Vibration Exercise in Individuals With Chronic Stroke. Phys Ther 95: 966-977. [Crossref]

212. McHam SA, Marwick TH, Pashkow FJ, Lauer MS (1999) Delayed systolic blood pressure recovery after graded exercise: an independent correlate of angiographic coronary disease. $\mathrm{J} \mathrm{Am} \mathrm{Coll} \mathrm{Cardiol} \mathrm{34:} \mathrm{754-759.}$

213. Laukkanen JA, Rauramaa R (2013) Systolic blood pressure during exercise testing and the risk of sudden cardiac death. Int J Cardiol 168: 3046-3047. [Crossref]

214. Laukkanen JA, Kurl S (2012) Blood pressure responses during exercise testing-is up best for prognosis? Ann Med 44: 218-224. [Crossref]

215. Laukkanen JA, Kurl S, Rauramaa R, Lakka TA, Venäläinen JM, et al. (2006) Systolic blood pressure response to exercise testing is related to the risk of acute myocardial infarction in middle-aged men. Eur J Cardiovasc Prev Rehabil 13: 421-428. [Crossref]

216. Michaelides AP, Psomadaki ZD, Aigyptiadou MN, Richter DJ, Andrikopoulos GK et al. (2003) Significance of exercise-induced ST changes in leads aVR, V5, and V1. Discrimination of patients with single- or multivessel coronary artery disease. Clin Cardiol 26: 226-230. [Crossref]

217. Dreyer RP, Beltrame JF, Neil C, Air T, Tavella R, et al. (2013) Cardiac hemodynamics in men versus women during acute ST-segment elevation myocardial infarction. Am J Cardiol 112: 143-149. [Crossref]

218. Hayashi M, Denjoy I, Hayashi M, et al. (2012) The role of stress test for predicting genetic mutations and future cardiac events in asymptomatic relatives of catecholaminergic polymorphic ventricular tachycardia probands. Europace 14:134451 .

219. Masri A, Pierson LM, Smedira NG, et al. (2015) Predictors of long-term outcomes in patients with hypertrophic cardiomyopathy undergoing cardiopulmonary stress testing and echocardiography. Am Heart J 169:684-92 e1.

220. Kindermann M, Seeland U, Ruhnke P, Böhm M, Maack C (2011) Functional effects of $\hat{I}^{2} \hat{a}, \square$-adrenoceptor polymorphisms on the hemodynamic response to dobutamine with and without $\hat{\mathrm{I}}^{2}$-blocker administration. Clin Res Cardiol 100: 129-137. [Crossref]

221. Magrì D, Corrà U, Di Lenarda A, Cattadori G, Maruotti A, et al. (2014) Cardiovascular mortality and chronotropic incompetence in systolic heart failure: the importance of a reappraisal of current cut-off criteria. Eur J Heart Fail16: 201-209. [Crossref]

222. Chandramouli B, Ehmke DA, Lauer RM (1975) Exercise-induced electrocardiographic changes in children with congenital aortic stenosis. J Pediatr 87: 725-730. [Crossref]

223. Lauer MS, Larson MG, Evans JC, Levy D (1999) Association of left ventricular dilatation and hypertrophy with chronotropic incompetence in the Framingham Heart Study. Am Heart $J$ 137: 903-909. [Crossref]

224. Singh JP, Larson MG, Manolio TA, O’Donnell CJ, Lauer M, et al. (1999) Blood pressure response during treadmill testing as a risk factor for new-onset hypertension. The Framingham heart study. Circulation 99: 1831-1836. [Crossref]

225. Lauer MS (1999) Resuscitating the exercise stress test. Cleve Clin J Med 66: 278-282. [Crossref]

226. Sung RJ, Lauer MR (2000) Sudden cardiac death syndrome: diagnosis and management. J Formos Med Assoc 99: 809-822. [Crossref]

227. Cura FA, Roffi M, Pasca N, et al. (2009) ST-segment resolution 60 minutes after 
combination treatment of abciximab with reteplase or reteplase alone for acute myocardial infarction (30-day mortality results from the resolution of ST-segment after reperfusion therapy substudy). Am J Cardiol 94:859-63.

228. Nishime EO, Cole CR, Blackstone EH, Pashkow FJ, Lauer MS (2000) Heart rate recovery and treadmill exercise score as predictors of mortality in patients referred for exercise ECG. JAMA 284: 1392-1398. [Crossref]

229. Tanindi A, Ugurlu M, Tore HF (2015) Blood pressure morning surge, exercise blood pressure response and autonomic nervous system. Scand Cardiovasc J 49: 220-227. [Crossref]

230. Hilz MJ, Intravooth T, Moeller S, Wang R, Lee DH, et al. (2015) Central Autonomic Dysfunction Delays Recovery of Fingolimod Induced Heart Rate Slowing. PLoS One 10: $\mathrm{e} 0132139$. [Crossref]

231. Ajijola OA, Howard-Quijano K, Scovotti J, Vaseghi M, Lee C, et al. (2015) Augmentation of cardiac sympathetic tone by percutaneous low-level stellate ganglion stimulation in humans: a feasibility study. Physiol Rep 3. [Crossref]

232. Cunha FA, Midgley AW, Gonçalves T, Soares PP, Farinatti P (2015) Parasympathetic reactivation after maximal CPET depends on exercise modality and resting vagal activity in healthy men. Springerplus 4: 100. [Crossref]

233. Imamura T, Kinugawa K, Okada I, Kato N, Fujino T, et al. (2015) Parasympathetic reinnervation accompanied by improved post-exercise heart rate recovery and quality of life in heart transplant recipients. Int Heart J 56: 180-185.

234. Voulgari C, Pagoni S, Vinik A, Poirier P (2013) Exercise improves cardiac autonomic function in obesity and diabetes. Metabolism 62: 609-621. [Crossref]

235. Shin KO, Yeo NH, Kang S (2010) Autonomic nervous activity and lipid oxidation postexercise with capsaicin in the humans. J Sports Sci Med 9: 253-261. [Crossref]

236. Ueno LM, Moritani T (2003) Effects of long-term exercise training on cardiac autonomic nervous activities and baroreflex sensitivity. Eur J Appl Physiol 89: 109114. [Crossref]

237. Best SA, Bivens TB, Dean Palmer M, Boyd KN, Melyn Galbreath M, et al. (2014) Heart rate recovery after maximal exercise is blunted in hypertensive seniors. $J$ Appl Physiol (1985) 117: 1302-1307. [Crossref]

238. Chou CL, Lee SH, Su YT, Hong SY, Pan BR, et al. (2014) Impact of Phase II cardiac rehabilitation on abnormal heart rate recovery. J Chin Med Assoc 77: 482-486. [Crossref]

239. Menêses AL, Forjaz CL, de Lima PF, Batista RM, Monteiro Mde F, et al. (2015)
Influence of endurance and resistance exercise order on the postexercise hemodynamic responses in hypertensive women. $J$ Strength Cond Res 29: 612-618. [Crossref]

240. Gielen S, Laughlin MH, O'Conner C, Duncker DJ (2015) Exercise training in patients with heart disease: review of beneficial effects and clinical recommendations. Prog Cardiovasc Dis 57: 347-355. [Crossref]

241. Erdei T, Smiseth OA, Marino P, Fraser AG (2014) A systematic review of diastolic stress tests in heart failure with preserved ejection fraction, with proposals from the EU-FP7 MEDIA study group. Eur J Heart Fail 16: 1345-1361.

242. Frolkis JP, Pothier CE, Blackstone EH, Lauer MS (2003) Frequent ventricular ectopy after exercise as a predictor of death. $N$ Engl J Med 348: 781-790. [Crossref]

243. Morshedi-Meibodi A, Larson MG, Levy D, O’Donnell CJ, Vasan RS (2002) Heart rate recovery after treadmill exercise testing and risk of cardiovascular disease events (The Framingham Heart Study). Am J Cardiol 90: 848-852. [Crossref]

244. Beckerman J, Mathur A, Stahr S, Myers J, Chun S, et al. (2005) Exercise-induced ventricular arrhythmias and cardiovascular death. Ann Noninvasive Electrocardiol 10: 47-52. [Crossref]

245. Dagres N, Hindricks G (2013) Risk stratification after myocardial infarction: is left ventricular ejection fraction enough to prevent sudden cardiac death? Eur Heart J 34 1964-1971. [Crossref]

246. Lauer MS, Pothier CE, Magid DJ, Smith SS, Kattan MW (2007) An externally validated model for predicting long-term survival after exercise treadmill testing in patients with suspected coronary artery disease and a normal electrocardiogram. Ann Intern Med 147: 821-8.

247. James S, Jhanji S, Smith A, O’Brien G, Fitzgibbon M, Pearse RM (2014) Comparison of the prognostic accuracy of scoring systems, cardiopulmonary exercise testing, and plasma biomarkers: a single-centre observational pilot study. Br J Anaesth 112: 491-7.

248. Duarte CV, Myers J, de Araújo CG3 (2015) Exercise heart rate gradient: a novel index to predict all-cause mortality. Eur J Prev Cardiol 22: 629-635. [Crossref]

249. Bucerius J, Joe AY, Herder E, et al. (2009) Hemodynamic variables during stress testing can predict referral to early catheterization but failed to show a prognostic impact on emerging cardiac events in patients aged 70 years and older undergoing exercise $(99 \mathrm{~m}) \mathrm{Tc}$-sestamibi myocardial perfusion scintigraphy. Int $J$ Cardiovasc Imaging 25: 569-79.

250. Ueshima K, Yamashina A, Usami S, et al. (2009) Prognostic value of myocardia perfusion SPECT images in combination with the maximal heart rate at exercise testing in Japanese patients with suspected ischemic heart disease: a sub-analysis of J-ACCESS. Ann Nucl Med 23: 849-54.

Copyright: (C2016 Sharif S. This is an open-access article distributed under the terms of the Creative Commons Attribution License, which permits unrestricted use, distribution, and reproduction in any medium, provided the original author and source are credited. 